\title{
Technological Change and the Growing Inequality in Managerial Compensation
}

\author{
Hanno Lustig, Chad Syverson, Stijn Van Nieuwerburgh* \\ UCLA Anderson, Chicago GSB and NYU Stern
}

January 15, 2009

\begin{abstract}
Three of the most fundamental changes in US corporations since the early 1970s have been (1) the increased importance of organizational capital in production, (2) the increase in managerial income inequality and pay-performance sensitivity, and (3) the secular decrease in labor market reallocation. Our paper develops a simple explanation for these changes: a shift in the composition of productivity growth away from vintage-specific to general growth. This shift has stimulated the accumulation of organizational capital in existing firms and reduced the need for reallocating workers to new firms. We characterize the optimal managerial compensation contract when firms accumulate organizational capital but risk-averse managers cannot commit to staying with the firm. A calibrated version of the model reproduces the increase in managerial compensation inequality and the increased sensitivity of pay to performance in the data over the last three decades.
\end{abstract}

${ }^{*}$ We are grateful to Jason Faberman, Carola Frydman, Enrichetta Ravina, and Scott Schuh for generously sharing their data with us. Lorenzo Naranjo and Andrew Hollenhurst provided outstanding research assistance. For helpful comments we would like to thank Andy Atkeson, Jonathan Berk, Nick Bloom, Murray Carlson, Xavier Gabaix, Ron Giammarino, Francois Gourio, Fatih Guvenen, Hugo Hopenhayn, Boyan Jovanovic, Arvind Krishnamurthy, Adriano Rampini, Kjetil Storesletten, and participants at the UCL conference on income and consumption inequality, the NBER Asset Pricing meetings in Cambridge, the Western Finance Association in Hawaii, Society for Economic Dynamics in Cambridge, the CEPR conference in Gerzensee, the AEA Meetings in San Francisco and seminar participants at Duke finance, NYU Stern finance, HBS finance, UBC finance, Wharton finance, INSEAD finance, Stanford economics, Kellogg finance, and the NYU macro lunch. This work is supported by the National Science Foundation under Grant No 0550910. 


\section{Introduction}

Three of the most fundamental changes in US corporations since the early 1970s have been (1) the apparent increase in the importance of organizational capital in production, (2) the increase in managerial income inequality and pay-performance sensitivity and (3) the secular decrease in labor market reallocation. Our paper provides an explanation for these changes.

This evidence is consistent with a shift in the composition of productivity growth away from vintage-specific growth, which only affects new firms, to more general productivity growth, which makes all firms more productive. In our model, the vintage-specific growth rate is the depreciation rate of organizational capital in existing firms. The shift allows successful firms to grow larger because their organizational capital effectively depreciates at a slower rate. This results in fewer firm exits and less labor reallocation from old to new firms. The growth composition shift allows our model to match the secular decline in the job reallocation rate in the US economy since the early 1970s, as documented by Davis, Haltiwanger, Jarmin and Miranda (2006) and Faberman (2006) 1 We attribute the change in the composition of productivity growth, the key driving force in the model, to the diffusion of information technology. However, our model applies to any other explanation for this shift, such as a change in the composition of the work force.

The change in productivity growth composition and the widespread accumulation of organizational capital that resulted creates a new problem for successful firms: how to distribute the rents from organizational capital? The firms' managers have de facto ownership rights on organizational capital, which makes it different from physical capital. These ownership rights arise from their ability to leave the firm, and to take some of its organizational capital to a new firm. Our paper studies the distribution of organizational rents between the owners and the managers in such an environment.

In the data, the dispersion of managerial compensation across firms is much wider now than 35 years ago. In large, successful firms, which accumulate a lot of organizational capital, managerial compensation has increased substantially, while it has not in small firms. We propose an equilibrium theory that ties the accumulation of organizational capital, induced by the shift in the composition of productivity growth, to managerial compensation. A calibrated version of the model can quantitatively account for a large share of these changes in the US economy.

The key element of the model is the optimal managerial compensation contract. This contract insures the risk averse manager against shocks to the firm's productivity. Insurance is provided because the manager can only work for one firm while the owner invests in a diversified portfolio of firms. But there is only partial insurance because the manager can quit and transfer some of the

\footnotetext{
${ }^{1}$ The declining volatility of firm growth rates, documented by Davis et al. (2006) for the entire universe of privately-held and publicly-traded firms, is consistent with this decline. Our model also implies that the fraction of output produced in older establishments increased, also consistent with the findings of Davis et al. (2006). The model of Jovanovic and Rousseau (2007) also relies on the decline in labor reallocation.
} 
organizational capital to a new firm. The degree of portability of organizational capital governs the value of the manager's outside option and determines how much risk sharing can be sustained between the manager and the owner. Dunne, Foster, Haltiwanger and Troske (2004) document a sizeable increase in within-industry between-establishment wage dispersion, while Frydman and Saks (2006)'s data show that this increase in dispersion is even higher for executives. A calibrated version of our model can match most of the increase in compensation inequality if we assume that half of the organizational capital is portable. However, this calibration can only match half of the observed increase in Tobin's q. Lowering the portability increases Tobin's q by more, but reduces the impact on compensation inequality. In the extreme case where organizational capital is not portable and managers can commit to stay, the change in the composition of productivity growth has no impact on compensation inequality.

Why does the growth composition shift increase the dispersion of managerial compensation? As long as firms are small, the manager's outside option constraint does not bind, and the optimal contract prescribes constant managerial compensation (relative to aggregate output). However, when a firm's size exceeds a threshold, optimal management compensation is increasing in the firm's organizational capital. The increased accumulation of organizational capital, resulting from the growth composition change, improves the manager's outside option in successful firms. To retain the manager, the owner of the firm increases compensation in response to high productivity. At the aggregate level, the change in the firm size distribution that results from the growth composition shift triggers an endogenous shift from low-powered to high-powered incentive compensation contracts. Such a shift seems consistent with the increased pay-performance sensitivity of employment contracts since the 1970s. If the manager is more impatient then the owner, this shift is further amplified.

Our model has several additional, "out-of-sample" implications which are borne out in the data. First, it matches the sensitivity of log compensation to log firm size in the U.S.; see Edmans, Gabaix and Landier (2007). Second, it matches the cross-sectional correlation between valuation and wage dispersion in the data. We identify high vintage-specific growth industries as those with low managerial wage dispersion. As predicted by the model, we find that these industries accumulate less organizational capital, using Tobin's q as our measure. The effects are large. We find that a one standard deviation increase in wage dispersion increases Tobin's q by 6 basis points using a broad measure of wage dispersion and by 14 basis points for executive compensation dispersion. These effects of executive wage compensation are stronger in industries with more intangibles. Wheeler (2005) shows that within-industry wage inequality is much higher in industries with higher frequency of computer usage, which are industries with lower vintage-specific growth in our model. 
Related Literature Our model combines the technology side of the vintage capital model of Atkeson and Kehoe $(2005,2007)$ with an optimal compensation contract for managers. The literature on optimal compensation contracts builds on Harris and Holmstrom (1982)'s seminal paper on optimal long-term wage contracts with learning about the manager's productivity. As in Harris and Holmstrom (1982), our optimal compensation dynamics display downward rigidity. This rigidity is generated by the inability of managers to commit to staying in the firm. There is scope for insurance when at least some of the organizational capital is specific to the match between the owner and the manager. Neal (1995) provides empirical evidence on the importance of match-specific capital. Related applications of optimal compensation contracts in finance are Berk, Stanton and Zechner (2005), Clementi, Cooley and Wang (2006), DeMarzo and Fishman (2007), Clementi and Hopenhayn (2002), and Albuquerque and Hopenhayn (2004), Falato and Kadyrzhanova (2008), DeMarzo and Sannikov (2006), Biais, Mariotti and Rochet (2007), Opp (2007), He (2007), and DeMarzo, Fishman, He and Wang (2007). Most of this work examines the optimal capital structure of the firm in the presence of moral hazard in partial equilibrium. Instead, our paper examines the optimal management compensation contract in the presence of portable capital in a general equilibrium model.

We use these contracts to connect changes in the distribution of firm size to changes in the distribution of managerial compensation. In closely related work, Gabaix and Landier (2008) explain the increased dispersion of CEO compensation in a matching model with an exogenously changing size distribution. Our paper endogenizes both the evolution of the size and the managerial compensation distribution and explicitly models the compensation contract. In addition, we derive a theoretical link between the size and book-to-market ratio of a firm and its labor compensation contracts. A related literature studies the relationship of firm characteristics such as leverage and riskiness of cash-flows to firm valuation in dynamic settings; see Gomes and Livdan (2004), Gomes and Schmid (2007), Hennessy and Whited (2007), Strebulaev (2007), Gourio (2007), Chen (2008). In recent work, Eisfeldt and Papanikolaou (2008) study the risk characteristics of organizational capital.

A large literature documents the increase of wage inequality in the US in the last three decades and its relation to technological change (Violante (2002), Guvenen and Kuruscu (2007), Autor, Katz and Kearny (2007), and Acemoglu (2002) for a survey). Our paper contributes to this literature by generating an endogenous switch to high-powered incentives contracts and by connecting the changing distribution of payouts to workers to the payouts to the owners of the capital stock, and ultimately to firm value. With the exception of Merz and Yahsiv (2003), Papanikolaou (2007), Bazdrech, Belo and Lin (2008), and Parlour and Walden (2008), the link between labor compensation and firm value is usually ignored in the literature. Parlour and Walden (2008) characterize optimal compensation contracts in the presence of moral hazard and derive predictions relating 
workers compensation, firm productivity, firm size and firm value.

One prominent example of the technological change we have in mind is the information technology revolution after 1973. As its efficiency improved and its price dropped, the use of IT spread, and its adoption affected all sectors of the economy. By now, there is overwhelming evidence that computers have fundamentally altered firms' business processes, relationships with customers and suppliers, and internal organization. E.g., Brynjolfsson and Hitt (1997, 2000), Bresnahan, Brynjolfsson and Hitt (2002), and an entire volume of contributions on organizational capital in the new economy by Corrado, Haltiwanger and Sichel, eds (2005). The literature convincingly argues that the gradual adoption of IT, a General Purpose Technology (Bresnahan and Trachtenberg (1996)), has increased the productivity of successful establishments of all vintages, not only the new ones. There is indirect evidence that organizational capital is more important in production than three decades ago from the stock market's valuation of US corporations; see e.g. Hall (2001). Moreover, organizational capital and IT are complementary inputs, and investment in IT has increased substantially since the 1970s (Bresnahan et al. (2002)). Finally, there is direct evidence on the link between IT and organizational capital and the increased importance of organizational capital. Using micro data, Bloom, Sadun and Van Reenen (2008) explain the productivity miracle in the US and its absence in Europe by means of a US advantage in IT that is "primarily due to its people management practices on promotions, rewards, hiring and firing".

Our paper is organized as follows. Section 2 defines the technology side of the model and the compensation contract between manager and owner, and defines an equilibrium with a continuum of managers and firms along a steady-state growth path. Section 3 highlights the properties of the optimal compensation contract along a steady-state growth path. Its dynamics are fully captured by the current and the highest-ever productivity level of the firm. Managerial compensation increases whenever a new maximum productivity level is reached. These two state variables have a natural interpretation as the size and market-to-book ratio of the firm. Our model ties these two characteristics to the value of the firm and the compensation of its management. Section 4 describes the calibration of the model. We introduce a gradual increase in general productivity growth and an offsetting reduction in vintage-specific productivity growth so that the total growth rate is constant. The magnitude of this compositional shift is calibrated to match the observed decline in labor reallocation. A second key parameter is the portability of organizational capital. It is calibrated to match the increase in income inequality. Interestingly, the model's cross-sectional distribution of managerial pay shares many features with the observed distribution: it is skewed, fat-tailed, and has the correct relation with firm size. The model also delivers an increase in pay-performance sensitivity similar to the one in the data. Finally, Section 5 provides additional cross-sectional evidence for the effect of managerial compensation inequality on valuations. 


\section{Model}

We set up a model with a fixed population (mass 1) of managers. Each manager is matched to an owner to form an establishment.2 The formation of a new establishment incurs a one-time fixed cost $S_{t}$. Establishments accumulate knowledge as long as the match lasts. We refer to this stock of knowledge as organizational capital $A_{t}$. This organizational capital affects the technology of production; it is a third factor of production besides physical capital and unskilled labor, earning organizational rents.

We assume that a part of the establishment's organizational capital is embodied in the manager. It is neither fully match-specific, as in Atkeson and Kehoe (2005), nor fully manager-specific. The main innovation of our work is to find the optimal division of organizational rents between the owner and the manager, as governed by an optimal long-term risk-sharing contract in the spirit of Harris and Holmstrom (1982). We solve for the optimal contract recursively (e.g., Thomas and Worall (1988) and Kocherlakota (1996)), but we use a different state variable from the one commonly used in the literature. The optimal contract maximizes the present discounted value of the organizational rents flowing to the owner subject to the manager's promise keeping constraint and a sequence of participation constraints that reflect the manager's inability to commit to the current match. We deviate from Krueger and Uhlig (2005) by assuming that the owner has limited liability. Separation occurs whenever there is no joint surplus left in the match. Upon separation, a fraction $0<\phi<1$ of the organizational capital can be transferred to the manager's next match, while the remainder is destroyed. If the manager could commit to staying in the match or if none of the organizational capital was destroyed when the manager left the firm, then the changing composition of productivity growth would have no effect on the distribution of compensation.

We start by setting up the model and defining a steady-state growth path. In Section 4 , we trace out the transition between two steady-state growth paths.

\section{$2.1 \quad$ Technology}

On the technology side, our model follows Atkeson and Kehoe (2005). Each establishment belongs to a vintage $s$. An establishment of vintage $s$ at time $t$ was born at $t-s$. An establishment operates a vintage-specific technology that uses unskilled labor $\left(l_{t}\right)$, physical capital $\left(k_{t}\right)$, and organizational capital $\left(A_{t}\right)$ as its inputs. Output generated with this technology is $y_{t}$ :

$$
y_{t}=z_{t}\left(A_{t}\right)^{1-\nu} F\left(k_{t}, l_{t}\right)^{\nu}
$$

\footnotetext{
${ }^{2}$ We use the words establishment and firm interchangeably. The manager can be interpreted as the entire management team.
} 
Following Lucas (1978), $\nu$ is the 'span of control' parameter of the manager. It governs the decreasing returns to scale at the establishment level.

There is no aggregate uncertainty in our model. There are two sources of productivity growth, which we label general and vintage-specific growth. The general productivity level $z_{t}$ grows at a deterministic and constant rate $g_{z}$ :

$$
z_{t}=\left(1+g_{z}\right) z_{t-1}
$$

General productivity growth affects establishments of all vintages alike. General productivity growth is often referred to as disembodied technical change. In addition, it is skill-neutral because it affects all three production inputs symmetrically.

Following Hopenhayn and Rogerson (1993), the match-specific level of organizational capital, $A_{t}$, follows an exogenous process. It is hit by random match-specific shocks $\varepsilon$, drawn from a distribution $N\left(0, \sigma^{2}\right)$ :

$$
\log A_{t+1}=\log A_{t}+\log \varepsilon_{t+1}
$$

We do not explicitly model the learning process that underlies the accumulation process of organizational capital. However, the $\varepsilon$ shocks can be interpreted as productivity gains derived from active or passive learning, from matching, or from adoption of new technologies in existing firms, as Atkeson and Kehoe (2005) point out 3

A new establishment can always start with a blue print or frontier technology level $\theta_{t}: A_{t} \geq \theta_{t}$. The productivity level of the blue print grows at a deterministic and constant rate $g_{\theta}$ :

$$
\theta_{t}=\left(1+g_{\theta}\right) \theta_{t-1}
$$

This vintage-specific growth is often referred to as embodied technical change.

\subsection{Contract Between Owner and Manager}

Owner There is a stand-in owner who is perfectly diversified.4 He maximizes the expected present discounted value of aggregate payouts from all establishments $D_{t}$ using a discount rate $r_{t}$ :

$$
E_{0} \sum_{t=0}^{\infty} e^{-\sum_{s=0}^{t} r_{s}} D_{t}=V_{t}+K_{t} .
$$

\footnotetext{
${ }^{3}$ Additionally, they can be interpreted as reduced-form for heterogeneity across managers, or for the outcomes from good or bad decisions made by the manager. Bertrand and Schoar (2003), Bennedsen, Perez-Gonzalez and Wolfenzon (2007), and Bloom and Van Reenen (2006) show that heterogeneity across managers leads to heterogeneity in firm outcomes. Jovanovic and Nyarko (1982) explicitly model learning-by-doing and McGrattan and Prescott (2007) and Carlin, Chowdhry and Garmaise (2008) explicitly model the accumulation of intangible capital.

${ }^{4}$ Equivalently, there is a continuum of atomless and identical owners.
} 
This object is the value of the aggregate capital stock $V_{t}+K_{t}$, which consists of the physical capital $K_{t}$ and the owner's residual claim to the aggregate rents from organizational capital, denoted $V_{t}$. The owner's value of organizational capital is the expected present discounted value of the aggregate stream of cash flows $\left\{\Pi_{t}\right\}$ that not already claimed by the other factors:

$$
\Pi_{t}=Y_{t}-W_{t} L_{t}-R_{t} K_{t}-C_{t}-S_{t}^{a},
$$

where $W_{t} L_{t}$ is the aggregate compensation of unskilled labor, $R_{t} K_{t}$ that of physical capital, $C_{t}$ the aggregate compensation of all the managers of the establishments, and $S_{t}^{a} \equiv N_{t} S_{t}$ the total sunk costs incurred for starting $N_{t}$ new establishments. Since we assume that the owner also owns the physical capital stock $K_{t}$, aggregate payouts to the owner $D_{t}$ are the sum of organizational rents and the factor payments to physical capital less physical investment:

$$
D_{t}=\Pi_{t}+R_{t} K_{t}-I_{t}, \forall t
$$

Since the sunk cost is lost, value-added is defined as $Y_{t}-S_{t}^{a}$.

An individual establishment's organizational rents (before sunk costs and physical capital income) accruing to its owners are defined with lower-case letters:

$$
\pi_{t}=y_{t}-W_{t} l_{t}-R_{t} k_{t}-c_{t}
$$

Manager The owner offers the manager a complete contingent contract $\left\{c_{t}\left(h^{t}\right), \beta_{t}\left(h^{t}\right)\right\}$ at the start of the match, where $c_{t}\left(h^{t}\right)$ is the compensation of the manager as a function of the history of shocks $h^{t}=\left(\varepsilon_{t}, \varepsilon_{t-1}, \ldots\right)$ and $\beta_{t}\left(h^{t}\right)$ is a governs whether the match is dissolved or not in history $h^{t}$. This contract cannot be renegotiated. The manager can always accept a job at another establishment, while the owner has limited liability.

The optimal contract maximizes the total expected payoff of the owner subject to delivering initial utility $v_{0}$ to the manager:

$$
v_{0}\left(h^{0}\right)=E_{h^{0}}\left[\sum_{\tau=0}^{\infty} e^{-\rho_{m} t} \frac{c_{\tau}\left(h^{\tau}\right)^{1-\gamma}}{1-\gamma}\right] .
$$

The manager is risk averse with CRRA parameter $\gamma$ and his time discount rate is denoted $\rho_{m}$. In general, the history-dependence of the manager's compensation makes this a complicated problem. However, as is common in the literature on dynamic contracts, we use the manager's promised utility as a state variable to make the problem recursive. The contract delivers $v_{t}$ in total expected utility to the manager today by delivering current compensation $c_{t}$ and state-contingent compensation promises $v_{t+1}(\cdot)$ tomorrow. These promised utilities lie on a domain $[\underline{v}, \bar{v}]$. 
We use $V_{t}\left(A_{t}, v_{t}\right)$ to denote the value of the owner's equity in an establishment with current organizational capital $A_{t}$, and an outstanding promise to deliver $v_{t}$ to the manager. It is the value of the owner's claim to the rents from organizational capital. This does not include the value of income from physical capital. Importantly, the owner has limited liability; the option to terminate the contract when there is no joint surplus in the match. Limited liability implies the constraint: $V_{t}\left(A_{t}, v_{t}\right) \geq 0$.

Finally, we use $\omega_{t}\left(A_{t}\right)$ to denote the outside option of a manager currently employed in an establishment with organizational capital $A_{t}$. When a manager switches to a new match, a fraction $\phi$ of the organizational capital is transferred to the next match and a fraction $1-\phi$ is destroyed. Free disposal applies: If the manager brings organizational capital worth less than the current blue print $\theta_{t}$, then the new match starts off with the blue print technology for the new vintage. Taken together, the organizational capital of a match of vintage $t$ is $\max \left\{\phi A_{t}, \theta_{t}\right\}$. The value of the outside option $\omega$ is determined in equilibrium by a zero-profit condition for new firm entry.

Recursive Formulation For given outside option $\left\{\omega_{t}\right\}$ and discount rate $\left\{r_{t}\right\}$ processes, the optimal contract in an establishment that has promised $v_{t}$ to its manager maximizes the owner's value $V$

$$
V_{t}\left(A_{t}, v_{t}\right)=\max \left[\widehat{V}_{t}\left(A_{t}, v_{t}\right), 0\right]
$$

and

$$
\widehat{V}_{t}\left(A_{t}, v_{t}\right)=\max _{c_{t}, v_{t+1}(\cdot)}\left[\pi_{t}+\int e^{-r_{t}} V\left(A_{t+1}, v_{t+1}\right) \Gamma\left(\varepsilon_{t+1}\right) d \varepsilon_{t+1}\right],
$$

by choosing the state-contingent promised utility schedule $v_{t+1}(\cdot)$ and the current compensation $c_{t}$, subject to the law of motion for organizational capital (2.1), a promise keeping constraint

$$
\begin{aligned}
v_{t}= & u\left(c_{t}\right)+e^{-\rho_{m}} \int \beta_{t+1}\left(v_{t}, \varepsilon_{t+1}\right) v_{t+1}\left(A_{t+1}\right) \Gamma\left(\varepsilon_{t+1}\right) d \varepsilon_{t+1} \\
& +e^{-\rho_{m}} \int \omega_{t+1}\left(A_{t+1}\right)\left(1-\beta_{t+1}\left(v_{t}, \varepsilon_{t+1}\right)\right) \Gamma\left(\varepsilon_{t+1}\right) d \varepsilon_{t+1}
\end{aligned}
$$

and a series of participation constraints

$$
v_{t+1}\left(A_{t+1}\right) \geq \omega_{t+1}\left(A_{t+1}\right) .
$$

The indicator variable $\beta$ is one if continuation is optimal and 0 elsewhere:

$$
\begin{aligned}
& \beta_{t+1}=1 \text { if } v_{t+1}\left(A_{t+1}\right) \leq v^{*}\left(A_{t+1}\right) \\
& \beta_{t+1}=0 \text { elsewhere. }
\end{aligned}
$$


The minimum at zero in equation (2.4) for the owner's value reflects limited liability of the owner: The match is terminated if the joint surplus of the match is negative. If the match is dissolved, the manager receives $\omega_{t+1}\left(A_{t+1}\right)$ in promised utility. To obtain this recursive formulation, we have used the fact that $V_{t}\left(A_{t}, \cdot\right)$ is non-increasing in its second argument. For each $A_{t}$, there exists a cutoff value $v^{*}\left(A_{t}\right)$ that satisfies $\widehat{V}_{t}\left(A_{t}, v^{*}\left(A_{t}\right)\right)=0$. The match is dissolved when the compensation promised to the manager exceeds the cutoff level: $\beta_{t+1}=0$ if and only if $v_{t+1}\left(A_{t+1}\right)>$ $v^{*}\left(A_{t+1}\right)$. Put differently, only establishments with high enough productivity $A_{t}>\underline{A}_{t}\left(v_{t}\right)$ survive.

\subsection{Equilibrium}

A competitive equilibrium is a price vector $\left\{W_{t}, R_{t}, r_{t}\right\}$, an allocation vector $\left\{k_{t}, l_{t}, c_{t}, \beta_{t}\right\}$, an outside option process $\left\{\omega_{t}\right\}$, and a sequence of distributions $\left\{\Psi_{t, s}, \lambda_{t, s}, N_{t}\right\}$ that satisfy optimality and market clearing conditions spelled out below.

Physical Capital and Unskilled Labor Unskilled labor $l$ and physical capital $k$ can be reallocated freely across different establishments. Hence, the problem of how much $l$ and $k$ to rent at factor prices $W$ and $R$, is entirely static. We use $K_{t}$ and $L_{t}$ to denote the aggregate quantities, and we use $\bar{A}_{t}$ to denote the average stock of organizational capital across all establishments and vintages:

$$
\bar{A}_{t}=\sum_{s=0}^{\infty} \int_{A} A \Phi_{t, s} d A,
$$

where $\Phi_{t, s}$ denotes the measure over organizational capital at the start of period $t$ for vintage $s$. Physical capital and unskilled labor are allocated in proportion to the establishment's organizational capital level $A_{t}$ :

$$
\begin{aligned}
k_{t}\left(A_{t}\right) & =\frac{A_{t}}{\bar{A}_{t}} K_{t} \\
l_{t}\left(A_{t}\right) & =\frac{A_{t}}{\bar{A}_{t}} L_{t} .
\end{aligned}
$$

This allocation satisfies the first order conditions and the market clearing conditions for capital and labor. The fact that establishments with larger organizational capital $A$ have more physical capital and hire more unskilled labor suggests an interpretation of $A$ as the size of the establishment.

The equilibrium wage rate $W_{t}$ for unskilled labor and rental rate for physical capital $R_{t}$ are determined by the standard first order conditions:

$$
W_{t}=\nu z_{t} \bar{A}_{t}^{1-\nu} F_{L}\left(K_{t}, L_{t}\right)^{\nu-1}, \quad R_{t}=\nu z_{t} \bar{A}_{t}^{1-\nu} F_{K}\left(K_{t}, L_{t}\right)^{\nu-1}
$$

The factor payments to unskilled labor and physical capital absorb a fraction $(1-\nu)$ of aggregate 
output $Y_{t}$, where $Y_{t}$ is given by:

$$
Y_{t}=z_{t} \bar{A}_{t}^{1-\nu} F\left(K_{t}, L_{t}\right)^{\nu}
$$

In the remainder, we assume a Cobb-Douglas production function $F(k, l)=k^{\alpha} l^{1-\alpha}$.

Organizational Rents A fraction $\nu$ of aggregate output $Y_{t}$ goes to organizational capital. These organizational rents are split between the owners $\Pi_{t}$, managers $C_{t}$, and sunk costs $S_{t}^{a}=N_{t} S_{t}$ :

$$
\sum_{s=0}^{\infty} \int_{v} \int_{A} \pi_{t}(A, v) \Psi_{t, s}(A, v) d(A, v)-N_{t} S_{t}=Y_{t}-W_{t} L_{t}-R_{t} K_{t}-C_{t}-S_{t}^{a}=\Pi_{t}
$$

where the measure $\Psi_{t, s}(A, v)$ is defined below. The second equality follows from (2.3) and ensures that the goods market clears.

Discount Rate The payoffs are priced off the inter-temporal marginal rate of substitution (IMRS) of the representative owner. Just like the manager, the owner has constant relative risk aversion preferences with parameter $\gamma$. His subjective time discount factor is $\rho_{o}$. Let $g_{t}$ denote the rate of change in $\log D_{t}$. Then, the equilibrium log discount rate or "cost of capital" $r_{t}$ is given by the owner's log IMRS:

$$
r_{t}=\rho_{o}+\gamma g_{t}
$$

Because there is no aggregate uncertainty and the owner holds a diversified portfolio of establishments, the cost of capital evolves deterministically. Thus, our setting is equivalent to one with a risk neutral owner who discounts future cash-flows, as in equation (2.2).

Managerial Compensation Having solved for the value function $\left\{V_{t}(\cdot, \cdot)\right\}$ that satisfies the Bellman equation above for given $\left\{\omega_{t}(\cdot), r_{t}\right\}$, we can construct the optimal contract for a new match starting at $t\left\{c_{t+j}\left(h^{t+j}\right), \beta_{t+j}\left(h^{t+j}\right)\right\}$ in sequential form.

Outside Option We assume the sunk cost $S_{t}$ grows at the same rate as output. Free entry stipulates that the equilibrium value of a new establishment to the owner is equal to the sunk cost $S_{t}$ :

$$
V_{t}\left(\max \left(\phi A_{t}, \theta_{t}\right), \omega_{t}\left(A_{t}\right)\right)=S_{t},
$$

The first argument indicates that a new establishment starts with organizational capital equal to the maximum of the frontier level of technology $\theta_{t}$ and the organizational capital $\phi A_{t}$ that the manager brought from the previous match. The total utility $\omega_{t}\left(A_{t}\right)$ promised to the manager at the start of a new match is such that the value of the new match is zero in expectation. Therefore, equation (2.9) pins down the equilibrium outside option $\omega_{t}\left(A_{t}\right)$. 
Law of Motion for Distributions We use $\chi$ to denote the implied probability density function for $A_{t+1}$ given $A_{t} . \kappa$ is an indicator function defined by the policy function for promised utilities: $\kappa\left(A^{\prime} ; A, v\right)=1$ if $v^{\prime}\left(A^{\prime} ; A, v\right)=v^{\prime}$, and equals 0 elsewhere. Using this indicator function, we can define the transition function $Q$ for $(A, v)$ :

$$
Q\left(\left(A^{\prime}, v^{\prime}\right),(A, v)\right)=\chi\left(A^{\prime} \mid A\right) \kappa\left(A^{\prime} ; A, v\right)
$$

We use $\Psi_{t, s}$ to denote the joint measure over organizational capital $A$ and promised utilities $v$ for matches of vintage $s$. Its law of motion is implied by the transition function:

$$
\Psi_{t+1, s+1}\left(A^{\prime}, v^{\prime}\right)=\int_{0}^{\infty} \int_{\underline{v}}^{\bar{v}} Q\left(\left(A^{\prime}, v^{\prime}\right),(A, v)\right) \lambda_{t, s}(A, v) d(A, v)
$$

where $\lambda_{t, s}(A, v)$ is the measure of surviving establishments in period $t$ of vintage $s$ :

$$
\lambda_{t, s}(A, v)=\int_{0}^{A} \int_{\underline{v}}^{v} \beta(a, u) d \Psi_{t, s}(a, u) \geq 0 .
$$

In equilibrium, the mass of new establishments created in each period $N_{t}$ (entry) equals the mass of matches destroyed in that same period (exit):

$$
N_{t}=\sum_{s=0}^{\infty} \int_{0}^{\infty} \int_{\underline{v}}^{\bar{v}}\left(1-\beta_{t, s}(A, v)\right) \Psi_{t, s}(A, v) d(A, v) \geq 0
$$

\subsection{Back-loading}

The free entry condition implies that the expected net present discounted value of a start-up is exactly zero:

$$
\int_{0}^{\infty} \int_{\underline{v}}^{\bar{v}} \sum_{j=0}^{\infty} e^{-\sum_{0}^{j} r_{s} d s} \pi_{t+j}(A, v) \Psi_{t+j, s}(A, v) d(A, v)-S_{t}=0
$$

Importantly, this does not imply that the organizational rents that flow to the owners are zero. As long as discount rates $r$ are strictly positive, the zero profit condition in (2.9) implies that expected net payouts are strictly positive:

$$
\int_{0}^{\infty} \int_{\underline{v}}^{\bar{v}} \sum_{j=0}^{\infty} \pi_{t+j}(A, v) \Psi_{t+j, s}(A, v) d(A, v)-S_{t}>0
$$

for two reasons. The first reason is a back-loading effect (see Atkeson and Kehoe (2005)). The owners are compensated for waiting in the form of positive payouts. The more back-loaded the payments are, the higher the expected payments. The expected payout profile of an establishment 
is steeply increasing: the first payout is a large negative number $\left(-S_{t}\right)$, the establishment then grows and starts to generate higher and higher profits (in expectation). Most of the organizational rents are paid in the future. Second, there is a selection effect operative. Only the establishments that have fast enough organizational capital growth (high enough $\varepsilon$ shocks) survive. When we compute aggregate (or expected) payouts, we are only sampling from the survivors who satisfy $A_{t}>\underline{A}_{t}\left(v_{t}\right)$.

As pointed out by Hopenhayn (2002), selection among establishments can explain why Tobin's (average) $q$ is larger than one on average. The aggregate value of establishments is given by the present discounted value of a claim to $\left\{D_{t}\right\}$. It equals the sum of all equity values across all establishment minus sunk costs plus the value of the physical capital stock $K_{t}$ :

$$
V_{t}^{a}=\sum_{s=0}^{\infty} \int_{0}^{\infty} \int_{\underline{v}}^{\bar{v}} V_{t}(A, v) \Psi_{t, s}(A, v) d(A, v)-S_{t}^{a}+K_{t} \geq K_{t}
$$

Tobin's q, $q_{t}=\frac{V_{t}^{a}}{K_{t}}$, is larger than one on average, in spite of the fact that new matches are valued at zero (net of their physical capital). The reason is again selection: when we compute q, we only sample survivors. For future reference, we also define aggregate managerial wealth in the economy as:

$$
M_{t}=\sum_{s=0}^{\infty} \int_{A} \int_{v} v_{t}(A, v) \Psi_{t, s}(A, v) d(A, v) .
$$

It is the value of a claim to all the rents from organizational capital that flow to the managers.

\subsection{Steady-State Growth Path}

In a first step, we solve for a steady-state growth path in which all aggregate variables grow at a constant rate. Aggregate establishment productivity $\left\{\bar{A}_{t}\right\}$ and the productivity of the newest vintage $\left\{\theta_{t}\right\}$ grow at a constant rate $g_{\theta}$, the variables $\left\{r_{t}, R_{t}, N_{t}\right\}$ are constant, the general productivity-level grows at a constant rate $g_{z}$, and all other aggregate variables grow at a constant rate

$$
g=\left(\left(1+g_{z}\right)\left(1+g_{\theta}\right)^{1-\nu}\right)^{\frac{1}{1-\alpha \nu}}
$$

We normalize the population of unskilled labor $L$ to one. To construct the steady-state growth path, we normalize organizational capital by the frontier level of technology, and we denote the resulting variable with a hat: $\widehat{A}_{t}=A_{t} / \theta_{t}$. By construction, $\widehat{A} \geq 1$ for a new establishment. A key insight is that the organizational capital of existing establishments, expressed in units of the frontier technology, shrinks at a rate $\left(1+g_{\theta}\right)$ :

$$
\log \left(\widehat{A}^{\prime}\right)=\log (\widehat{A})-\log \left(1+g_{\theta}\right)+\log \left(\varepsilon^{\prime}\right)
$$


The prime denotes next period's value. The lower $g_{\theta}$, the higher the growth rate of $\widehat{A}$. Below, we introduce a secular decline in $g_{\theta}$. Appendix B contains a detailed definition of a steady-state growth path. It shows how to express all other variables in efficiency units. Those variables are denoted by a tilde in rescaled units. Finally, it reformulates the optimal contract along the steady-state growth path. The Bellman equation is defined over the rescaled variables.

\section{Properties of Compensation Contract}

Although the managerial compensation contract allows for complicated history-dependence, the optimal contract along a steady-state growth path turns out to have intuitive dynamics. Two state variables summarize all necessary information: the current level of productivity $A_{t}$, which we have given an interpretation as the size of the establishment, and the highest level of productivity recorded thus far $A_{\max , t}$, which we will give an interpretation as the book-to-market ratio of the establishment.

\subsection{No Discount Rate Wedge}

First, we consider the case in which the manager and the owner are equally impatient $\left(\rho_{m}=\right.$ $\left.\rho_{o}\right)$. The promised utility state variable $v_{t}$ can be replaced by the running maximum of the productivity process: $\widehat{A}_{\max , t}=\max \left\{\widehat{A}_{\tau}, \tau \leq t\right\}$. We let $T$ denote the random stopping time when the establishment is shut down:

$$
T=\inf \left\{\tau \geq 0: \widehat{V}\left(\widehat{A}_{\tau}, \widetilde{v}_{\tau}\right)=0\right\}
$$

Proposition. Optimal management compensation along a steady-state growth path is determined by the running maximum of productivity: $\tilde{c}_{t}\left(\widehat{A}_{\max , t}\right)=\max \left\{c_{0}, C\left(\omega\left(\widehat{A}_{\max , t}\right), \widehat{A}_{\max , t}\right)\right\}$ for all $0<t<T$ where the function $C(\widetilde{v}, \widehat{A})$ is defined such that the implied compensation stream $\left\{\widetilde{c}_{\tau}\right\}_{\tau=t}^{\infty}$ delivers total expected utility $\widetilde{v}_{t}$ to the manager.

Management compensation is constant relative to the productivity of the blueprint as long as the running maximum is unchanged. The constancy is optimal because of the concavity of the manager's utility function, and arises as long as the participation constraint does not bind. When the productivity process reaches a new high, the participation constraint binds, and the compensation is adjusted upwards. Armed with this result, we can define the owner's value recursively as a function of $\widehat{A}_{t}$ and the running maximum $\widehat{A}_{\max , t}$ :

$$
\widetilde{V}\left(\widehat{A}, \widehat{A}_{\max }\right)=\max \left[\widehat{V}\left(\widehat{A}, \widehat{A}_{\max }\right), 0\right]
$$


and

$$
\widehat{V}\left(\widehat{A}, \widehat{A}_{\max }\right)=\widetilde{y}-\widetilde{W} l-R \widetilde{k}-\widetilde{c}\left(\widehat{A}_{\max }\right)+e^{-\left(\rho_{o}-(1-\gamma) g\right)} \int \widetilde{V}\left(\widehat{A}^{\prime}, \widehat{A}_{\max }^{\prime}\right) \Gamma\left(\varepsilon^{\prime}\right) d \varepsilon^{\prime},
$$

subject to the law of motion for organizational capital in (2.13) and the implied law of motion for the running maximum.

Figure 1 illustrates the dynamics of the optimal compensation. It plots $\widehat{A}$ on the vertical axis against $\widehat{A}_{\max }$ on the horizontal axis. By definition, $\widehat{A} \leq \widehat{A}_{\max }$, so that only the area on and below the 45-degree line is relevant. New establishments start with $\widehat{A}=\widehat{A}_{\max } \geq 1$. When an establishment grows and this growth establishes a new maximum productivity level, it travels along the 45-degree line. When its productivity level falls or increases but not enough to establish a new record, it travels along a vertical line in the $\left(\widehat{A}_{\max }, \widehat{A}\right)$ space. The region $[0,1 / \phi]$ for $\widehat{A}_{\max }$ is an insensitivity region. Managerial compensation is constant $\left(\tilde{c}=c_{0}\right)$ in this region. Compensation is constant for small establishments because of the sunk cost. The manager will not leave because his productivity level is insufficiently high to justify a new sunk cost. To the right of this region, managerial compensation is pinned down by the binding outside option that was last encountered: $\tilde{c}\left(\widehat{A}_{\max }\right)$. As long as current productivity stays below the running maximum, the manager's compensation is constant. Along this $\Delta \tilde{c}=0$ locus, the variation in current productivity is fully absorbed by the net payouts to owners, as long as $A_{t}$ stays above the $\widehat{V}=0$ locus. The owner bears all downside idiosyncratic productivity risk. When productivity falls below this locus, the match is terminated.

[Figure 1 about here.]

Growth and Value In the $\left(\widehat{A}_{\max }, \widehat{A}\right)$ space, there is a line with slope $\phi$ along which the owner's value is constant: $\widehat{V}=\widehat{S}$. This is the locus of pairs for which $\widehat{A}=\phi \widehat{A}_{\max }$. On this locus, an existing establishment pays the same compensation as a new establishment and it has the same productivity:

$$
\widehat{V}\left(\phi \widehat{A}_{\max }, \omega\left(\widehat{A}_{\max }\right)\right)=\widehat{S}
$$

This means that the firm's market-to-book ratio, or average $q$ ratio, on this line is given by:

$$
q=1+\frac{\widehat{V}\left(\widehat{A}, \widehat{A}_{\text {max }}\right)}{\widehat{k}(\widehat{A})}=1+\frac{\widehat{S}}{\widehat{k}(\widehat{A})}
$$

This suggests a natural interpretation of the ratio of current productivity relative to the running maximum as an indicator of the market-to-book ratio. Compare two establishments with the same size $\widehat{A}$. The establishment with the lower ratio of $\widehat{A} / \widehat{A}_{\max }$ has the same physical capital stock $\widehat{k}(\widehat{A})$, but higher (current and future) managerial compensation. This is because the manager is compensated for the best past performance, which is substantially above current productivity. 
Hence, the value of its organizational capital going to the owners $\widehat{V}\left(\widehat{A}, \widehat{A}_{\text {max }}\right)$ is lower. These low $\widehat{A} / \widehat{A}_{\text {max }}$ firms have a low market-to-book ratio $1+\widehat{V} / \widehat{k}$. They are value firms. High $\widehat{A} / \widehat{A}_{\text {max }}$ firms are growth firms. In Figure 1, firms with the same market-to-book ratio are on the same line through the origin. Value firms are farther from the 45-degree line, growth firms are closer.

Organizational Capital as Collateral The limited portability of organizational capital creates the collateral in the matches necessary to sustain risk sharing. Two extreme cases illustrate this point. In the first case, there is no capital specific to the match and there are no other frictions, as in Krueger and Uhlig (2005). The manager can transfer $100 \%$ of the organizational capital of the establishment to a future match $(\phi=1)$ and there are no sunk costs $(\widehat{S}=0)$. When $\phi=1$ in Figure 1, the $\widehat{V}=\widehat{S}$ line coincides with the 45-degree line. Therefore, $\widehat{V} \leq \widehat{S}=0$ everywhere. Limited liability then implies that $\widehat{V}=0$. Because there is no relationship capital, no risk sharing can be sustained, and the managers earn all the rents from organizational capital. The value of the owner's stake in the organizational capital is zero. This implies that Tobin's q equals one for all $t$.

In the second case that we consider, $\phi=0$ : all of the organizational capital is match-specific. This is the case considered by Atkeson and Kehoe (2005). The insensitivity regions extends over the entire domain of $\widehat{A}$. The manager's outside option is constant so that perfect risk sharing can be sustained. There is zero dispersion in managerial compensation. The owner receives all organizational rents, which is reflected in high q ratios.

Compensation and Payout Dynamics We use a random 300-period simulation from a calibrated version of the model to illustrate the compensation dynamics; the details of the calibration are in section 4.2. Figure 2 tracks a single, successful establishment through time. The left panel plots the realized $\left(\widehat{A}_{\max , t}, \widehat{A}_{t}\right)$ values, as in Figure 1. The right panel shows the corresponding time series for productivity (or size) $\widehat{A}$ (solid line, measured against the left axis) and managerial compensation $\widetilde{c}$ (dashed line, measured against the right axis). Because $\phi=0.5$, the insensitivity regions extends until $\widehat{A}=2$. In that region the compensation is constant. When the establishment size exceeds 2 , around period 50, and leaves the insensitivity region, managerial compensation starts to increase in response to increases in $\widehat{A}$, i.e. every time a new running maximum for $\widehat{A}$ is attained. The establishment moves along the 45 -degree line in the left panel in the $\left(\widehat{A}_{\text {max }, t}, \widehat{A}_{t}\right)$ space. The manager's compensation does not track the downward movements in productivity/size that occur between periods 75 and 100. This is the first vertical locus of points in the left panel. The second big run-up in productivity increases the manager's compensation once more. Eventually, when the productivity level drops below the lower bound $\underline{A}(v)$, the owner's residual value equals zero $\widehat{V}=0$, the match is dissolved, and the manager switches to a new match. This endogenous break-up is indicated by an arrow. A new match start off at productivity level max $(\phi \widehat{A}, 1)$. This 
second match only lasts for about 20 periods because of poor productivity shock realizations. The third match on the figure lasts longer, but the establishment never leaves the insensitivity region, so that wages are constant.

[Figure 2 about here.]

Figure 3 compares the managers payouts $\tilde{c}$ (left panel) and the owner's payouts $\tilde{\pi}$ (right panel) for the same history of shocks as the previous figure. The left panel is identical to the right panel in Figure 2. The key message of the figure is that the owner's payouts are more sensitive to productivity shocks than the manager's compensation. The dashed line in the right panel is more volatile than the dashed line in the left panel. In the insensitivity region, the owner bears all the risk from fluctuating productivity. In addition, whenever the productivity level falls below the running maximum, the owner's payouts absorb the entire decline in output. This is because the owner provides maximal insurance to the risk-averse manager.

[Figure 3 about here.]

\subsection{Discount Rate Wedge}

In the benchmark case with equal rates of time preference for the managers and the owners, managerial compensation does not respond to decreases in firm size and productivity. The management is completely "entrenched". In the quantitative section of the paper, we consider a less extreme version, by allowing for a wedge between the discount rates of the management and the owners. In particular, we consider the case in which the manager discounts cash flows at a higher rate than the owner $\left(\rho_{m}>\rho_{o}\right)$. This is the relevant case when the manager faces binding borrowing constraints, has a lower willingness to substitute consumption over time, or simply has a higher rate of time preference. This is a standard assumption in this literature; see DeMarzo et al. (2007) for a recent example.

Proposition. Let $t_{\max }$ denote the random stopping time that indicates when the participation constraint was last binding: $t_{\text {max }}=\sup \left\{\tau \geq 0: \omega\left(\widehat{A}_{\tau}\right)=\widetilde{v}_{\tau}\right\}$. Optimal management compensation evolves according to: $\widetilde{c}_{t}=c\left(\widehat{A}_{t_{\max }}\right) e^{-\gamma\left(\rho_{m}-\rho_{o}\right)\left(t-t_{\max }\right)}$ for all $0<t$. We define $c\left(\widehat{A}_{t_{\max }}\right)$ such that $\left\{\widetilde{c}_{\tau}\right\}_{\tau=t_{\max }}^{\infty}$ delivers total expected utility $\omega\left(\widehat{A}_{t_{\max }}\right)$ to the manager.

Instead of $\widehat{A}_{\text {max }}$, the new state variable is a discounted version of the running maximum; it depreciates at a rate that is governed by the rate of time preference gap between the manager and the owner. In the absence of binding participation constraints, managerial compensation $c$ grows at a rate smaller than the rate of value-added on the steady-state growth path. Put differently, whenever the current productivity of the establishment declines below its running maximum, the 
manager's scaled compensation $\tilde{c}$ drifts down. The left panel of Figure 4 illustrates this downward drift, for example between periods 150 and 200. Management is less "entrenched". This feature will help to match equilibrium entry and exit rates in the data. Without it, the model generates too much entry and exit.

[Figure 4 about here.]

\section{Transition Experiment}

We feed a gradual increase in general productivity growth into the model: $g_{z} \uparrow$. To keep the analysis tractable, we assume that the total productivity growth rate of the economy $g_{t}$ is constant at its initial steady-state growth path value 5

$$
g=\left[\left(1+g_{t, z}\right)\left(1+g_{t, \theta}\right)^{1-\nu}\right]^{\frac{1}{1-\alpha \nu}}
$$

Holding fixed $g$, the increase in $g_{z}$ corresponds to a decrease in the rate of depreciation of organizational capital $\widehat{A}$ in the stationary version of the model: $g_{\theta} \downarrow$. The growth composition change allows existing firms in traditional industries to remain competitive longer, and grow larger. Their organizational capital depreciates less quickly in 2005-2008 than in 1970-74 (see equation 2.13).

In Figure 1, a lower $g_{\theta}$ has two distinct effects. First, it reduces the rate at which $\widehat{A}$ drifts down along a vertical line. Second, it shifts more probability mass to higher realizations of $\widehat{A}_{\max }$. So, a decrease in $g_{\theta}$ shifts more probability mass closer to the 45-degree line, and more mass in the northeast quadrant. Thus, the the growth composition change creates larger establishments and more of them are growth rather than value firms. The increased importance of growth firms seems intuitively consistent with the notion of the IT revolution.

Establishments accumulate more organizational capital and are longer-lived in the new steady state. Because more establishments grow larger, the managers' outside option constraint binds more frequently. This increases the sensitivity of pay to performance. In addition, the arrival of more large establishments increases the back-loading of the owner's payouts. This raises the owner's average payouts in the cross-section as a fraction of output. Managerial compensation, in contrast, is more front-loaded.

We study the transition between a low and a high general-purpose innovation growth path. At $t=0$, agents know the entire future path for $\left\{g_{t, \theta}\right\}_{t=0}^{T}$, although the arrival of the GPT itself at $t=0$ is not anticipated at $t=\ldots,-2,-1$. Appendix C defines the constant cost-of-capital transition. It also explains the reverse shooting algorithm we use to solve for prices and quantities

\footnotetext{
${ }^{5}$ First, there is little evidence that the last 35 years have seen higher average GDP growth $g$ than the 35-year period that preceded it. Second, changing GDP growth along the transition path is computationally challenging.
} 
along the transition path. This is a non-trivial problem because we need to keep track of how the cross-sectional distribution of $(A, v)$ evolves over time. We then simulate the economy forward for a cross-section of 5,000 establishments, starting in the initial steady state. We assume the change in the relative importance of growth rates is accomplished in 20 years. However, the economy continues to adjust substantially afterwards on its way to the final steady state.

\subsection{Target Moments in the Data}

Several of the model's parameters were chosen to match moments of the data we describe below. This is true for the decline in job reallocation, the increase in wage dispersion, and the initial exit rate.

Increased Dispersion in Compensation We provide three sources of data, all of which document a large increase in wage inequality. The first and broadest measure studies wages of all workers. The data are from the Quarterly Census of Employment and Wages (QCEW) collected by the Bureau of Labor Statistics (BLS). The unit of observation is an establishment, and the data report the average wage. We calculate the within-industry wage dispersion from a panel of 55 2-digit SIC-code industries, and average across industries. Panel A of Table VI shows that the cross-sectional standard deviation of log wages increased by 7.3 , the IQR by 5.4 , and the IDR by 14.7 percentage points between 1975-1979 and 2000-2004.6

The second body of evidence comes from managerial wages. While our model has implications for overall wage inequality, managerial data arguably provide a cleaner match. We use wage income data from the March Current Population Survey and select only workers in managerial occupations (See Appendix A.4). Panel B of TableVI shows that in this sample, the cross-sectional standard deviation of $\log$ wages increased by 9.4 , the IQR by 11.3 , and the IDR by 19.6 percentage points between 1975-1979 and 2000-2004. Hence the increase in managerial compensation is more pronounced than for the population at large.

The third and most narrow metric focusses on the top of the compensation scale. Measure total compensation (salaries, bonuses, long-term bonus payments, and the Black-Scholes value of stock option grants) for the three highest-paid officers in the largest 50 firms, Frydman and Saks (2006) documents a strong increase in executive compensation. Panel C of Table VI uses the same data to show an equally spectacular increase in the dispersion of top managers' compensation.7

\footnotetext{
${ }^{6}$ According to Dunne et al. (2004), increasing within-industry, between-establishment wage dispersion accounts for a large fraction of the increase in overall income inequality in the US. This is true especially for non-production workers, which includes managers. They study US manufacturing establishments. Between 1977 and 1988, the between-plant coefficient of variation for non-production worker's wages increased from $44 \%$ to $56 \%$, while the within-plant dispersion actually decreased. They also document a similar increase in the dispersion of productivity between plants.

${ }^{7}$ We thank Carola Frydman for graciously making these data available to us.
} 
Since the mid-1970s, the cross-sectional standard deviation of log compensation increased by 43 log points, the IQR and IDR more than doubled to 1.5 and 2.6, respectively. The inequality and the increase in inequality are strongest for this group of executives.

[Table 1 about here.]

Declining Excess Job Reallocation The excess job reallocation rate is a direct measure of the cross-sectional dispersion of establishment growth rates. It is defined as the sum of the job creation rate plus the job destruction rate less the net employment growth rate. Before 1990, we only have establishment-level reallocation data for the manufacturing sector. Figure 5 shows that the excess reallocation rate in manufacturing declined from $10.9 \%$ in $1965-1969$ to $8.4 \%$ in $2000-2005$, and further to 7.8\% between 2006 and 2007.III. After 1990, the BLS provides establishment-level data for all sectors of the economy. Over the 1990-2007 sample, the excess reallocation rate declined from 10.6 to $7.2 \%$ in manufacturing, from 15 to $12.4 \%$ in services, and from 15.6 to $12.3 \%$ in the entire private sector. Half of this decline is due to a decline in entry and exit rates for establishments, from $4 \%$ to $2.5 \%$. The other half is due to a decline in expansions and contractions of existing establishments.

[Figure 5 about here.]

Similar trends have been documented in firm-level (rather than establishment-level) data. Davis et al. (2006) document large declines in the dispersion and the volatility of firm growth rates for the US economy, either measured based on employment or sales growth. The employment-weighted dispersion of firm growth rates declined from .70 in 1978 to .55 in 2001, while the employmentweighted volatility of firm growth rates declined from .22 in 1980 to .12 in 2001. The former measures the cross-sectional standard deviation of firm growth rates, while the latter measures the standard deviation of firm growth rates over time 8 This decline in volatility is present across sectors.

Finally, Haltiwanger and Schuh (1999) constructs a proxy for establishment-level reallocation by studying intra-industry job flows. This is the only economy-wide series that is continually available for our sample period. The excess reallocation rate for the non-financial sector declines from $19 \%$ in 1960 to an average of $11.5 \%$ in 2000 . This $19-11.5 \%$ change is what we calibrate to in our benchmark model.

\footnotetext{
${ }^{8}$ Comin and Philippon (2005) show that there is an increase in volatility for the sub-sample of publicly traded firms. Our analysis is for the entire non-financial sector, publicly-traded and privately-held. The discrepancy between the findings for public and for all firms may have to do with private firms that go public earlier. The IPO decision is outside of our model.
} 
Valuation The increase in the payouts to securities holders over the last 30 years coincided with a doubling of Tobin's average $q$ and the value-output ratio. Tobin's q is measured as the market value of US non-financial corporations, constructed from the Flow of Funds data divided by the replacement cost of physical capital:

$$
q_{t}=1+\frac{V_{t}^{a}}{K_{t}}
$$

We construct the replacement cost of physical capital using the perpetual inventory method with FoF investment and inventory data (see Appendix A.1). The first column in Table VII shows that Tobin's q decreased from 2.0 in the 1965-1969 period to 1.0 in the 1975-1979 period. After that, it gradually increases to 2.6 in the 1995-1999 period and then it levels off to 2.3 and 2.0. The value-output ratio for the US corporate sector, reported in Column (2), is computed as the ratio of $V_{t}^{a}$ to gross value-added $Y_{t}$. It tracks the evolution of Tobin's q almost perfectly.

The value of US corporations per unit of physical capital has more than doubled since the late seventies. The increase in valuations seems to be linked to the accumulation of organizational capital rather than physical capital. Note that the secular increase in Tobin's q cannot be explained solely by a decrease in taxes. Indeed, in a model without organizational capital and no adjustment costs, Tobin's q is always one. In a world with reasonable adjustment costs, a decrease in taxes could increase Tobin's q above one, but only temporarily. Finally, the large deviations of Tobin's $\mathrm{q}$ from one occur in the second half of the sample when the average tax rate is slightly increasing.

[Table 2 about here.]

\subsection{Benchmark Parameter Choices}

In order to assess its quantitative implications, we calibrate the model at annual frequency. Table [1 summarizes the parameters.

Production Technology and Preferences The parameter $\nu$ governs the decreasing returns to scale at the establishment level. It is set to .75, at the low end of the range considered by Atkeson and Kehoe (2005). The other technology and preferences parameters are chosen to match the depreciation, the average capital-to-output ratio and the average cost of capital for the US non-financial sector over the period 1950-2005. The depreciation rate $\delta$ is calibrated to .06 based on NIPA data. Next, we calibrate the Cobb-Douglas productivity exponent on capital, $\alpha$. Because there is no aggregate risk, the rate of return on physical capital is deterministic in the model. In equilibrium, that rate equals the discount rate. Both are fixed along the transition path. From the Euler equation for physical capital, we get:

$$
r=\left(1-\delta+\alpha \nu \frac{Y}{K}\right)
$$


We compute the cost of capital $r$ in the data as the weighted-average realized return on equity and corporate bonds; it is $5.5 \%$. The weights are given by the observed leverage ratio 9 The average capital-to-output ratio is 1.77 . The above equation then implies $\alpha \nu=0.23$. As a result, $\alpha=0.30$.

We choose the rate of time preference of the owner $\rho_{o}=.02$ such that his subjective time discount factor is $\exp \left(-\rho_{o}\right)=.98$. In our benchmark results, we assume that the manager is less patient: $\rho_{m}=.03$. Finally, we choose a coefficient of relative risk aversion $\gamma=1.6$. This is the value that solves equation (2.8) given our choices for $r, \rho_{o}$, and given the average growth rate of real aggregate output of $g=0.022$.

Organizational Capital Accumulation and Portability To calibrate the organizational capital accumulation, its portability, and the sunk costs of forming a new match, we match the excess job reallocation rate and the firm exit rate in the initial steady state to those observed in the data in 1970-74, and we match the increase in managerial wage inequality to that in the data.

Following Atkeson and Kehoe (2005), we assume the $\varepsilon$ shocks are log-normal with mean $m_{s}$ and standard deviation $\sigma_{s}$. We abstract from the dependence on these parameters on the vintage $s$. For parsimony, the mean $m_{s}$ is set zero. However, younger matches (lower $s$ ) will grow faster in equilibrium because of selection, even without age-dependence in $m_{s}$. The standard deviation $\sigma_{s}=\sigma$ of these shocks is chosen to generate an excess job reallocation rate of $19 \%$ in the initial steady state. This choice matches the 1970-74 reallocation rate in the data. The size of the sunk cost $(S)$ is chosen to match the entry-exit rates in the initial steady state. The sunk cost is equal to 6.5 times the annual cash flow generated by the average firm. This delivers an entry/exit rate of $4.3 \%$ in the initial steady-state, again matching the 1970-74 data. The portability or matchspecificity parameter $\phi$ governs the increase in wage dispersion in the model. We set it equal to 0.5, which means that $50 \%$ of organizational capital is transferable to a next match. This value of the parameter enables the model to match the increase in intra-industry wage inequality.

Productivity Growth Composition In the baseline experiment, we assume the change in the composition of growth to $g_{n e w, z}$ occurs over 20 years, and we assume it starts in 1971. After 20 years, in 1990, productivity growth settles down at $\left(g_{n e w, z}, g_{n e w, \theta}\right)$. The actual transition to a new steady-state growth path takes much longer. The change in the composition of growth is calibrated to match the decline in reallocation rates in the data from $19 \%$ to $11 \%$. General productivity growth increases from $g_{\text {old }, z}=0.3 \%$ in the initial steady state to $g_{\text {new }, z}=1.45 \%$ in the new steady-state. Correspondingly, vintage-specific productivity growth decreases from $g_{\text {old }, \theta}=5.5 \%$ to $g_{\text {new }, \theta}=0.8 \%$.

\footnotetext{
${ }^{9}$ Since the model has no taxes, but there are taxes in the data, we take into account the corporate tax rate $(28 \%)$ in the calculation of the cost of capital. Appendix D provides more details on the cost of capital calibration.
} 


\subsection{Main Results: Compensation and Size Distribution}

We start by comparing the size and compensation distribution in the initial and final steady states, as well as its evolution during the transition.

Figure 6 illustrates how a relatively modest change in the size distribution of firms, brought about by a change in the composition of productivity growth, translates in a much larger change in the distribution of compensation. The left panel plots the log compensation of managers $(\log \tilde{c})$ against the $\log$ of establishment size $(\log \widehat{A})$ in the initial steady-state growth path of the model. The right panel shows the same plot for the final steady state growth path. Each dot represents one establishment in the cross-section. The key to the amplification is the compensation contract. The optimal contract features a lower bound on size below which the manager's compensation does not respond to changes in size. Above a certain size, the manager's compensation only responds to good news about the establishment's productivity. In the initial steady state, few establishments become large enough to exceed the insensitivity range. Managerial compensation hardly responds to changes in size; there is little cross-sectional variation in compensation. The right panel shows that this is no longer true in the new steady-state. Establishments live longer on average and the successful ones grow larger. The log size distribution is more skewed than in the initial steadystate. The figure shows a strong positive cross-sectional relationship between size and managerial compensation. Thus, the model endogenously generates a shift from low-powered to high-powered incentive compensation contracts.

[Figure 6 about here.]

On the new steady-state growth path, the distribution of managerial compensation has much fatter tails than the size distribution, as shown in Figure 7 . Its left panel shows the histogram of log compensation in the new steady state; the right panel is the histogram of log size. Both were demeaned. The distribution of managerial compensation is more skewed and it has fatter tails than the size distribution. The kurtosis of log compensation is 19.82, compared to 3.38 for log size. The skewness is 3.81 for log compensation, compared to .47 for log size.

[Figure 7 about here.]

There is a large finance literature that studies compensation for top managers (e.g., Frydman and Saks (2006) and Kaplan and Rauh (2007)). Gabaix and Landier (2008) and other studies have documented that managerial compensation is well-described by a power function of size, a finding referred to as Roberts' law. In our model too, the compensation distribution has much fatter tails than a log-normal. On average, the relation between compensation and size in the new steady

state satisfies $\log \widetilde{c}=\alpha+\kappa \log \widehat{A}$. The slope coefficient $\kappa$ is .24 in the new steady-state, close to the value of $1 / 3$ found in the empirical literature. Our model therefore not only provides a rationale 
for the large and skewed increase in managerial compensation, but is also quantitatively consistent with the observed size-compensation distribution.

The model has implications for the size distribution of firms. Luttmer (2005) and others show that the size distribution for large firms follows a Pareto distribution. The same is true for the large firms in our new steady-state. Figure 8 shows that the relation between log rank and log size is linear for large establishments. Quantitatively, the model's Pareto coefficient is 1.5 whereas the tails in the data are slightly thicker with a Pareto coefficient of 1.10 For small firms, the relationship is less steep, a finding reminiscent of the city-size literature.

[Figure 8 about here.]

Table II reports the impact of the change in the composition of growth on the distribution of compensation and productivity. The log of establishment productivity (TFP) is given by (1 $\nu) \log \widehat{A}$. The $\log$ of the manager's wage is given by $\log \widetilde{c}$. The left panel reports the crosssectional standard deviation, the inter-quartile range ( $I Q R$ or $75^{\text {th }}$ minus $25^{\text {th }}$ percentiles), and the inter-decile range ( $I D R$ or $90^{t h}$ minus $10^{t h}$ percentiles) for log wages; the right panel does the same for log TFP. The first (last) line shows the values in the initial (final) steady-state. The numbers in between are five-year averages computed along the transition path. Small changes in the productivity (or size) distribution cause big changes in the distribution of compensation. The standard deviation of managerial compensation increases by 7.3 percentage points in the first 35 years of the transition, similar to what we report later for the increase in within-industry wage dispersion in the data 11 In the next ten years from 2006-2015, the standard deviation of log wage dispersion is predicted to increase by another 4.5 percentage points and the $I D R$ by as much as 11.5 percentage points 12 In sum, the shift towards high-powered incentives leads to a substantial increase in income inequality.

To summarize, in the benchmark version of the calibrated model, the standard deviation of log managerial compensation increases by 11 log points, the IQR by 8 log points and the IDR by 9 log points over the same period. The IDR increases another 11 log points in the following five years. This compares favorably to the data for workers and managers in Panel A and B in Table VI. Finally, the model produces and increase of $50 \mathrm{log}$ points in the IDR for the largest 500 establishments, $58 \mathrm{log}$ point for the largest 50 establishments (see Table III). Of course, this number still falls short of the 130 log points increase for top management in the largest 50 firms. In the high portability case, the increase in the IDR is $80 \log$ points. This massive increase in compensation inequality is generated by a modest increase in productivity dispersion. As the right

\footnotetext{
${ }^{10}$ We follow Gabaix and Ibragimov (2007) who estimate the Pareto coefficient $b$ from a regression of the form $\log ($ Rank-1/2)=a-b $\log ($ Size $)$.

${ }^{11}$ In the model, unskilled wages are equalized across establishments and do not affect the dispersion.

${ }^{12}$ In the new steady-state, compensation becomes very skewed: the IDR increases so much that the IQR actually decreases.
} 
columns show, the standard deviation of productivity increases by only 1.5 percentage points in the first 35 years of the transition. The $I Q R$ for increases from 18.3 to $18.4 \%$ and the $I D R$ from 29.2 to $31.8 \%$ over the same period. Overall, productivity dispersion in our model is somewhat smaller than what is found in the data. Using 1977 US manufacturing data at the 4-digit industry level, Syverson (2004) reports a within-industry IQR of log TFP between 29 and 44\%. Increasing log TFP dispersion in the model would give rise to too much reallocation, absent other frictions.

Table III reports the sensitivity of managerial compensation to size for the 500 largest and 50 largest establishments in the model's simulated panel. The top panel looks at the benchmark calibration. We measure the sensitivity of managerial compensation to size by running a separate cross-sectional regression of $\Delta \log c^{i}$ on $\Delta \log A^{i}$ in each time period. The slope of that regression is referred to as the pay-performance elasticity. Columns (1) and (5) report the slope coefficients (multiplied by 100) for the 500 and 50 largest firms, respectively. Columns (2) to (4) and (6) to (8) report the dispersion of log compensation for these two samples. For the 500 largest firms, the payperformance elasticity increases from 0 to 5.86. I.e., every percent increase in size translates into .056 percent increase in compensation. However, for the 50 largest establishments, the elasticity increases from 3.4 to 46. In the data, Murphy (1998) finds that the cash compensation elasticity for CEOs of S\&P500 companies increases from 8 in 1972 to 40 in 1996.13

\subsection{Labor Reallocation, Exit, and Firm Valuation}

The right panel of Table II summarizes the other main aggregates of interest. The first column shows the excess job reallocation rate. We calibrate the shift in the composition of productivity so as to match the initial steady-state value of $19 \%$ as well as the subsequent decline to $12.2 \%$ over the ensuing 35 years. The model successfully matches the decline in entry/exit rate (on a steady-state growth path those are identical). The exit rate starts from $4.3 \%$ (chosen to match the sunk costs) and declines to $3.0 \%$ by 2001-05. In the data, it declined from $4 \%$ to $2.5 \%$. The exit rate is highest in the first ten years of the transition because there is a shake-out of establishments that are no longer profitable under the increased managerial compensation.

The last three columns of Table report valuation ratios. As establishments start to live longer and accumulate more organizational capital, the aggregate value of organizational capital starts to increase. This is the same selection effect: We are only sampling the survivors when computing the market value of matches. Correspondingly, Tobin's q increases from 1.4 in 1971-75 to 1.6 in 2001-05 (Column (9)). The value of organizational capital as a fraction of value-added $V_{t} /\left(Y_{t}-S_{t}^{a}\right)$ increases from 0.83 to 1.18, a $42 \%$ increase (Column (10)). The increase in the data from 1.54 to

\footnotetext{
${ }^{13}$ These elasticities are based on annual regressions of $\Delta \log ($ Cash Compensation $)$ on $\log (1+$ Shareholder Return $)$. Cash compensation includes salaries, bonuses, and small amounts of other cash compensation. Data prior to 1992 are from Forbes Annual Compensation Surveys; data for 1992 and later are from Compustats ExecuComp database.
} 


\subsection{1 represents a $45 \%$ increase (See Section 4.1).}

Managerial workers capture only part of this increase in organizational rents because of the sunk costs and limited portability of organizational capital. The sunk costs create an insensitivity range in which managerial compensation does not respond to productivity shocks. In addition, the discount rate wedge imputes a downward drift to the managerial compensation. As matches live longer, managers end up with a smaller share of the surplus. Managerial wealth declines from $8.3 \%$ of value-added to $7.2 \%$ (Column $7, M /\left(Y-S^{a}\right)$ ). The model thus implies a large transfer of wealth from the managers to the owners. However, there is an enormous amount of heterogeneity in the evolution of managerial wealth to value-added $\left(M /\left(Y-S^{a}\right)\right)$, echoing the increase in managerial compensation dispersion documented earlier. We sort all managers by their final steady-state $M /\left(Y-S^{a}\right)$ - ratio. Managers in the $95^{t h}$ percentile saw a large increase, managers in the $90^{t h}$ percentile maintained the status quo, while all other managers (especially those in the smaller establishments) suffered a decline in wealth. Managers in the $5^{\text {th }}$ see their wealth decline from 8 to 6.5 times (per capita) value added.

\subsection{Robustness}

The degree of portability $\phi$ governs several key aspects of the model. We studied both a higher value $(\phi=.75)$ and a lower value $(\phi=0)$ than our benchmark case $(\phi=.50)$. These results are reported in Table IV and Table $\mathrm{V}$. More portability amplifies the dispersion effect of the shift in productivity growth composition, but lowers the increase in the valuation ratios.

The left panel of Table IV shows the compensation and productivity distribution along the transition for the case in which all of the organizational capital is match-specific $(\phi=0)$. As we expected, the model no longer generates any increase in managerial compensation inequality. Indeed, the managers are fully insured and the owners capture a larger share of the organizational rents. The same results obtain in the case in which managers can fully commit to staying in the match.

This all translates into to larger increases in the owners' wealth relative to value-added and in Tobin's q ratio. These results are reported in the left panel of Table V. Tobin's q goes up from 1.38 to 1.84 , a substantially larger increase than in the benchmark case. In sum, the predictions for valuation ratios improve, but the predictions for wage dispersion are counter-factual.

In contrast, increasing $\phi$ to a value of 0.75 gives managers more ownership rights to organizational capital. The right panel of Table $[\mathrm{IV}$ shows the compensation and productivity distribution. As a result, not only is initial income dispersion higher (the standard deviation of log wages is $9.6 \%$ instead of $0.9 \%$ in the initial steady-state), the increase in dispersion is also higher. The standard deviation increases by 15 , the IQR by 8 and the IDR by 42 percentage points from the initial situation to 2001-05. These increases are much larger than in the benchmark case and fit 
the increase in managerial income inequality in the data better. Some other desirable features of the $\phi=.75$ calibration are that (i) Robert's coefficient, which measures the elasticity of managerial compensation to firm size, is 0.32 , now matching the data exactly, and (ii) the Pareto coefficient of the firm size distribution is 1.05, also matching the empirical estimates around 1. However, the increase in valuation ratios is only half as big as in the benchmark case.

\section{Additional Evidence from the Cross-Section}

This section explores the cross-sectional relationship between managerial compensation dispersion on the one hand and firm valuation on the the other hand, first in the model and then in the data. The empirical evidence for the cross-sectional evidence on the link between wage dispersion and firm valuation in the data, and the model's ability to generate a similar link, lend further credibility to the organizational capital accumulation mechanism we have put forward.

Our analysis so far focused on the time-series relationship between the composition of productivity growth, the reallocation rate, and Tobin's q. In the model, these same relationships hold in the cross-section. We use the calibrated model to illustrate this mechanism. We compute 13 different steady-state growth paths for 13 different economies, we label "industries." All parameters are constant across economies except for the vintage-specific growth rate $g_{\theta}$, which we vary in equally-spaced increments from a low value of $0.00 \%$ to a high value of $6.82 \%$. Figure 9 plots the Tobin's q ratio for each industry against its dispersion of managerial compensation. Reading from the left to the right, as the vintage-specific growth rate declines, the average Tobin's q increases and so does the dispersion in managerial wage dispersion. Recalling Figure 2, a larger mass of firms stays closer to the 45 degree line in such low vintage-specific growth industries.

The sensitivity of the valuations to changes in the reallocation rate is much higher for industries with a low $g_{\theta}$ area. Moving from the point labeled "1" to point "2" on Figure9, Tobin's q decreases by 50 basis points in response to a 100 log points decrease in the dispersion of compensation. In the data discussed below, estimates of the corresponding decrease in Tobin's q vary between 111 and 70 basis points if we use a broad measure of wage dispersion and between 50 and 80 basis points if we focus only on executive compensation dispersion. The same size increase in $g_{\theta}$, such as the change from point 3 to 4 , has smaller effects on $q$ and wage dispersion when $g_{\theta}$ is higher.

[Figure 9 about here.]

In the data, we identify high vintage-specific growth $\left(g_{\theta}\right)$ industries, who experience faster depreciation of organizational capital, as those with lower cross-sectional dispersion in managerial compensation. The key question then becomes whether industries characterized by higher dispersion also have lower valuation ratios. We build a panel of 55 industries at the 2-digit SIC 
level covering the 1976-2005 sample. As before, we exclude the financial sector to end up with 47 industries; see Appendices A.2 and A.3 for details. We examine the cross-sectional relationship between compensation dispersion and the average Tobin's q in this panel of 47 industries. We use two different measures for the average Tobin's q. The first measure (Tobin's q1) uses total assets less financial assets at book value in the denominator. The second measure (Tobin's q2) uses the book value of total assets in the denominator. The numerator in both ratios is the market value of the firm. Appendix A.2 provides more details.

Our first estimation uses the cross-sectional standard deviation of log wages among the establishments within an industry from QWEC. We include fixed effects for time and industry in these regressions. The results are reported in Table VIII. Our second estimation uses individual-level wage data for executives from Execucomp to form the wage dispersion in an industry. These results are reported in Table IX. For ease of comparison, we focus on the common sample 1992-2005. The establishment-level data are available at quarterly frequency, while the executive data analysis is at annual frequency. In the latter case, we average Tobin's q across the quarters in a year.

Columns (1) and (3) of Table VIII show that there is a significantly positive covariation between wage dispersion and Tobin's q1 and q2 using the establishment-level data. The point estimates imply that a one standard-deviation increase in the wage dispersion of a region (within-region variation) increases Tobin's q1 by 0.063 and Tobin's q2 by 0.046. A region with a one standard deviation higher wage dispersion (across-region variation), has a Tobin's q1 (q2) that is 0.417 (0.303) higher. In specifications (2) and (4), we control for intangibles and continue to find strong positive correlation between the wage dispersion in an industry and its q ratio. While the interaction effect is negative, the overall effect of wage dispersion is positive (last row). We find similarly strong effects if we use the inter-quartile range of log wages instead of the standard deviation (not reported).

[Table 3 about here.]

Table IX repeats the same analysis using a measure of wage dispersion for executives (See appendix A.5). Wage dispersion is the cross-sectional standard deviation of the log wage among executives within an industry. Executive wage dispersion in an industry is significantly positively related to both measures of Tobin's q (Columns (1) and (3)). A one standard deviation increase in the within-industry wage dispersion (0.161) translates into a 0.123 increase in Tobin's q1 and a 0.076 increase in Tobin's q2. The marginal effect of wage dispersion on Tobin's q slightly increases after controlling for the intangibles ratio of the industry (Columns (2) and (4)). In this specification, the effect of executive wage dispersion on Tobin's q is stronger in industries with a higher intangibles ratio. For example, in Column 2, the industry with the average intangible ratio shows a sensitivity to a (within) one standard deviation increase in WDISP of 0.133 , whereas that sensitivity increases to 0.143 for an industry with an intangible ratio that is one standard deviation above the average. 
The results are very similar when using the value of options exercised instead of options granted in the wage definition (not reported). The results using the inter-quartile range of log wages are also similar (not reported), suggesting a robust correlation between managerial wage dispersion and Tobin's q.

[Table 4 about here.]

To sum up, we find that firms in high wage dispersion, low reallocation industries tend to have higher Tobin's q, as predicted by the model. In these industries, successful firms accumulate more organizational capital.

\section{Conclusion}

In the last three decades, there has been a marked increase in managerial compensation inequality and in the sensitivity of compensation to performance. This paper argues that both changes can be tied to a compositional change in the nature of productivity growth and the increases in organizational capital that resulted from it. In our model, establishments combine organizational capital, physical capital and unskilled labor to produce output. The division of organizational rents between the owner and the manager of the establishment is governed by a long-term compensation contract. The well-diversified owner offers insurance to the risk averse manager, but this insurance is limited by the manager's ability to leave and by the owner's limited liability. Because the manager can transfer a fraction of the organizational capital to a future employer, the increased accumulation of organizational capital improves the outside option of managers in successful firms, and the manager's compensation increases in response to positive performance. In small, unsuccessful firms, compensation is insensitive to performance. The change in the composition of productivity growth allows successful establishments to accumulate more organization capital and grow larger. Together they account for the increase in compensation inequality. In addition, the model generates an increase in firm valuation relative to the physical capital or to output, which reflects the higher value of organizational capital. It is also broadly consistent with trends in labor reallocation, the firm size distribution, and firm exit and entry. 


\section{References}

Acemoglu, Daron, "Technical Change, Inequality and the Labor Market," Journal of Economic Literature, 2002, 40(1), 7-72.

Albuquerque, Rui and Hugo Hopenhayn, "Optimal Lending Contracts and Firm Dynamics," Review of Economic Studies, 2004, 71(2), 285-315.

Atkeson, Andrew and Patrick Kehoe, "Modeling and Measuring Organizational Capital," Journal of Political Economy, 2005, 113, 1026-1053.

and __ , "Modeling the Transition to a New Economy: Lessons from Two Technological Revolutions," American Economic Review, 2007, Forthcoming.

Autor, David H., Lawrence F. Katz, and Melissa S. Kearny, "Trends in U.S. Wage Inequality: Revising the Revisionists," March 2007. NBER Working Paper No. 11627.

Bazdrech, Santiago, Frederico Belo, and Xioajin Lin, "Labor Hiring, Investment, and Stock Return Predictability in the Cross-Section," October 2008. Working paper University of Minnesota.

Bennedsen, Morten, Francisco Perez-Gonzalez, and Daniel Wolfenzon, "Do CEOs Matter?," March 2007. Working Paper NYU Stern.

Berk, Jonathan, Richard Stanton, and Josef Zechner, "Human Capital, Bankruptcy and Capital Structure," 2005. Working Paper University of California at Berkeley.

Bertrand, Marianne and Antoinette Schoar, "Managing with Style: The Effect of Managers on Firm Policies," Quarterly Journal of Economics, 2003, 118 (4), 1169-1208.

Biais, Bruno, Thomas Mariotti, and Jean-Charles Rochet, "Dynamic Security Design: Convergence to Continuous Time and Asset Pricing Implications," Review of Economic Studies, 2007, 74 (2), 345-390.

Bloom, Nicholas and John Van Reenen, "Measuring and Explaining Management Practices Across Firm and Countries," May 2006. NBER Working Paper No 12216.

_ _ Raffaella Sadun, and John Van Reenen, "Americans Do I.T. Better: U.S. Multinationals And The Productivity Miracle," April 2008. Stanford University.

Bresnahan, Tim and M. Trachtenberg, "General Purpose Technologies: Engines of Growth," Journal Of Econometrics: Annals of Econometrics, 1996, 65, 83-108. 
_ _ Erik Brynjolfsson, and Lorin M. Hitt, "Information Technology, Workplace Organization, and the Demand for Skilled Labor: Firm-Level Evidence," Quarterly Journal of Economics, 2002, 117(1), 339-76.

Brynjolfsson, Erik and Lorin M. Hitt, "Information Technology and Internal Firm Orgaanization: An Exploratory Analysis," Journal of Management Information Systems, 1997, 14(2), 81-102.

and _ _ "Beyond Computation: Information Technology, Organizational Transformation and Business Performance," Journal of Economic Perspectives, 2000, 14(4), 23-48.

Carlin, Bruce Ian, Bhagwan Chowdhry, and Mark J. Garmaise, "Investment in Organizational Capital," June 2008. Working Paper UCLA Anderson.

Chen, Hui, "Macroeconomic Conditions and the Puzzles of Credit Spreads and Capital Structure," January 2008. Working Paper MIT.

Clementi, Gian Luca and Hugo A. Hopenhayn, "A Theory of Financing Constraints and Firm Dynamics," Quarterly Journal of Economics, 2002, 121(1), 229-265.

, Thomas Cooley, and Cheng Wang, "Stock Grants as a Commitment Device," Journal of Economic Dynamics and Control, 2006, 30 (11), 2191-2216.

Comin, Diego and Thomas Philippon, "The Rise in Firm-Level Volatility: Causes and Consequences," NBER Macroeconomics Annual, 2005.

Corrado, Carol, John Haltiwanger, and Daniel Sichel, eds, Measuring Capital in the New Econommy, National Bureau of Economic Research, 2005.

Davis, Steven J., John Haltiwanger, Ron Jarmin, and Javier Miranda, "Volatility and Dispersion in Business Growth Rates: Publicly Traded Vs. Privately Held Firms," NBER Working Paper, 2006, 12354.

DeMarzo, Peter and Michael Fishman, "Optimal Long-Term Financial Contracting with Privately Observed Cash Flows," Review of Financial Studies, 2007, 20(6), 2079-2128. Working Paper Stanford University.

and Yuliy Sannikov, "A Continuous-Time Agency Model of Optimal Contracting and Dynamic Capital Structure," Journal of Finance, 2006, 61 (6), 2681-2724.

, Michael Fishman, Zhiguo He, and Neng Wang, "Dynamic Agency and the q Theory of Investment," 2007. Working Paper Stanford University. 
Dunne, Timothy, Lucia Foster, John Haltiwanger, and Kenneth R. Troske, "Wage and Productivity Dispersion in United States Manufacturing: The Role of Computer Investment," Journal of Labor Economics, 2004, 22(2), 397-428.

Edmans, Alex, Xavier Gabaix, and Augustin Landier, "A Calibratable Model of Optimal CEO Incentives in Market Equilibrium," September 2007. Working Paper Wharton and New York University.

Eisfeldt, Andrea L. and Dimitris Papanikolaou, "Organization Capital and the Cross-Section of Expected Returns," November 2008. Working paper Kellogg School.

Faberman, Jason, "Job Flows and The Recent Business Cycle: Not All Recoveries Are Created Equal.," BLS Working Paper, 2006, 391.

Falato, Antonio and Dalida Kadyrzhanova, "Optimal CEO Incentives and Industry Dynamics," February 2008. Working Paper University of Maryland.

Frydman, Carola and Raven E. Saks, "Executive Compensation: A New View from a LongRun Perspective, 1936-2005," 2006. Working Paper MIT Sloan.

Gabaix, Xavier and Augustin Landier, "Why Has CEO Pay Increased so Much?," Quarterly Journal of Economics, 2008, Forthcoming.

and Rustam Ibragimov, "Rank-1/2: A Simple Way to Improve the OLS Estimation of Tail Exponents," September 2007. NBER Technical Working Paper No 342.

Gomes, Joao and Dmitry Livdan, "Optimal Diversification: Reconciling Theory and Evidence," Journal of Finance, 2004, 59, 507-535.

and Lukas Schmid, "Levered Returns," 2007. Working Paper Wharton.

Gourio, Francois, "Labor Leverage, Firm's Heterogeneous Sensitivities to the Business Cycle, and the Cross-Section of Expected Returns," October 2007. Working Paper Boston University.

Guvenen, Fatih and Burhanettin Kuruscu, "A Quantitative Analysis of the Evolution of the U.S. Wage Distribution: 1970-2000," September 2007. Working Paper University of Texas at Austin.

Hall, Robert E., "The Stock Market and Capital Accumulation," American Economic Review, 2001, 91, 1185-1202.

Haltiwanger, John C. and Scott Schuh, "Gross job flows between plants and industries," New England Economic Review, 1999, March/April. 
Harris, Milton and Bengt Holmstrom, "A Theory of Wage Dynamics," Review of Economic Studies, 1982, 49, 315-333.

He, Zhiguo, "Dynamic Compensation Contract with Private Savings," December 2007. Working Paper Northwestern University.

Hennessy, Christopher A. and Toni Whited, "How Costly is External Financing? Evidence from a Structural Estimation," Journal of Finance, 2007, 62 (4), 1705-1744.

Hopenhayn, Hugo, "Exit, selection, and the value of firms," Journal of Economic Dynamics and Control, 2002, 16(3-4), Pages 621-653.

and Richard Rogerson, "Job Turnover and Policy Evaluation: A General Equilibrium Analysis," Journal of Political Economy, 1993, 101, 915-38.

Jovanovic, Boyan and Peter Rousseau, "Specific Capital and Technological Variety," December 2007. Working Paper New York UNiversity.

and Yaw Nyarko, "Learning by Doing and the Choice of Technology," Econometrica, 1982, 50 (6), 1345-70.

Kaplan, Steven N. and Joshua Rauh, "Wall Street and Main Street: What Contributes to the Rise in the Highest Incomes?," July 2007. Working Paper University of Chicago.

Kocherlakota, Narayana, "Implications of Efficient Risk Sharing Without Commitment.," Review of Economic Studies, 1996, 63, 595-610.

Krueger, Dirk and Harald Uhlig, "Competitive Risk Sharing with Costly Recontracting," Journal of Monetary Economics, 2005, Forthcoming.

Lucas, Robert, "Asset Prices in an Exchange Economy," Econometrica, 1978, 46 (6), 1429-54.

Luttmer, Erzo, "Growth and the Size Distribution of Firms," Working Paper Federal Reserve Bank of Minneapolis, 2005.

McGrattan, Ellen and Edward C. Prescott, "Unmeasured Investment and the Puzzling Boom in the 1990s," October 2007. NBER Working Paper No 13499.

Merz, Monika and Eran Yahsiv, "Labor and the Value of the Firm," CEPR Discussion Paper, 2003, 965.

Murphy, Kevin J., "Executive Compensation," April 1998. Available at SSRN: http://ssrn.com/abstract $=163914$. 
Neal, Derek, "Industry-Specific Capital: Evidence Form Displaced Workers," Journal of Labor Economics, 1995, 13, 653-77.

Opp, Marcus M., "Expropriation Risk and Technology," November 2007. Working Paper University of Chiacgo.

Papanikolaou, Dimitris, "Investment-specific Technology Shocks and Asset Prices," April 2007. Working Paper Kellogg.

Parlour, Christine A. and Johan Walden, "Capital, Contracts and the Cross Section of Stock Returns," May 2008. Working Paper Haas School of Business.

Strebulaev, Ilya, "Do Tests of Capital Structure Theory Mean What They Say?," Journal of Finance, 2007, 62, 1747-1787.

Syverson, Chad, "Product Substitutability and Productivity Dispersion," Review of Economics and Statistics, 2004, 86(2), 534-550.

Thomas, Jonathan and Tim Worall, "Self-Enforcing Wage Contracts," Review of Economic Studies, 1988, 15, 541-554.

Violante, Giovanni L., "Skill Transferability, Technological Acceleration and the Rise in Residual Wage Inequality," Quarterly Journal of Economics, 2002, 117 (1), 297-338.

Wheeler, Christopher H., "Evidence on Wage Inequality, Worker Education, and Technology," Federal Reserve Bank Of St. Louis Review, 2005, May/June, 375-394.

\section{A Data Appendix}

\section{A.1 Using Flow of Funds Data}

The computation of firm value returns is based on Hall (2001). The data to construct our measure of returns on firm value were obtained from the Federal Flow of Funds, henceforth FoF. 14 We use the (seasonally-unadjusted) flow tables for the non-farm, non-financial corporate sector, in file UTABS 102D. We calculate the market value of the corporate sector $V^{a}$ as the market value of equity (item 1031640030) plus net financial liabilities. Net financial liabilities are defined as financial liabilities (item 144190005) minus financial assets (item 144090005). Because outstanding bonds (a part of financial liabilities) are valued at book value, we transform them into a market value using the Dow Jones Corporate Bond Index. We construct the levels from the flows by adding them up, except for the Market Value of Equity. This series is downloaded directly from the Balance series BTABS 102D. (item 103164003).

\footnotetext{
${ }^{14}$ Data are available at http://www.federalreserve.gov/ RELEASES/z1/current/data.htm
} 
Net (aggregate corporate) pay-outs is measured as dividends (item 10612005) plus the interest paid on debt (from the NIPA Table 1.14 on the Gross Product of Non-financial, Corporate Business, line 25) less the net issuance of equity (item 103164003) less the increase in net financial liabilities (item 10419005).

The same NIPA Table 1.14 is used to obtain gross value-added (line 17), $Y_{t}-S_{t}^{a}$.

Finally, capital expenditures (item 105050005) are obtained from the Flow of Funds.

Tobin's q for the non-financial sector is constructed as the ratio of the market value of the corporate sector $V^{a}$ and the replacement cost of physical capital $(K)$. We construct the replacement cost of physical capital using the perpetual inventory method with FoF investment data (item 105013003) and inventory data (item 10502005). To deflate the series, we use the implicit deflator for fixed non-residential investment from NIPA, Table 7.1. The depreciation rate is set to $2.6 \%$ per quarter.

\section{A.2 Using Compustat Data}

We use annual and quarterly data from Compustat 15 If an item from Compustat is not available quarterly, we use its annual figure for each quarter, dividing by four if it is a flow variable. For each industry, the net payout ratio is defined as the ratio of payouts to security holders over payouts to workers plus security holders.

Payouts Payouts to security holders are computed as the sum of interest expense (item 22), dividends from preferred stock (item 24), dividends from common stock (item 20) and equity repurchases, computed as the difference between the purchase (annual item 115) and the sale (annual item 108) of common and preferred stock. If there is no information available on the purchase and sale of stock, we assume that it is zero.

Payouts to workers are computed as the product of number of employees (Compustat, annual item 29) and wages per employee (see Appendix A.3 below). We only include those firms for which the payouts to security holders is less than the firm assets (annual item 6).

The intangibles ratio is defined as the ratio of intangibles (annual item 33) to net property, plant and equipment (PPE, annual item 8). We filter out those firms whose intangibles ratio is greater than 1000. The intangibles ratio for each industry is then computed as the total intangibles over the total PPE for each industry.

Tobin's q The variable $q_{1}$ is computed first for all firms having the following items available from COMPUSTAT: DATA1 (Cash and Short-Term Investments), DATA2 (Receivables - Total), DATA6 (Assets Total), DATA9 (Long-Term Debt - Total), DATA34 (Debt in Current Liabilities), DATA56 (Preferred Stock - Redemption Value), DATA68 (Current Assets - Other), and the following items available from CRSP: PRC (Closing Price of Bid/Ask average), SHROUT (Number of shares outstanding). For each

\footnotetext{
${ }^{15}$ Data are available at http://wrds.wharton.upenn.edu/
} 
firm, Tobin's q is defined as follows

$$
q_{1}=\frac{\text { totalvaluefirm }}{\text { DATA6 - fin_assets }}
$$

where:

$$
\begin{gathered}
\text { totalvaluefirm }=\text { mcap }+ \text { totaldebt }- \text { fin_assets } \\
\text { totaldebt }=D A T A 9+D A T A 34+D A T A 56 \\
\text { fin_assets }=D A T A 1+D A T A 2+D A T A 68 \\
\text { mcap }=P R C * S H R O U T / 1000 .
\end{gathered}
$$

We select only those firms for which $0<q_{1}<100$. For the selected firms, we compute industry I's Tobin's $q$ as :

$$
q_{1, \text { agg }}=\frac{\sum_{i \in I} \text { totalvaluefirm }_{i}}{\sum_{i \in I} \text { DATA }_{i}-\text { fin_assets }_{i}} .
$$

We use a second definition of Tobin's q. The variable $q_{2}$ is defined as :

$$
q_{2}=\frac{\text { firm_value }}{\text { DATA6 }}
$$

where

$$
\begin{gathered}
\text { firm_value }=\text { mcap }+D A T A 6-D A T A 60-D A T A 74 \\
m c a p=P R C * S H R O U T / 1000
\end{gathered}
$$

and computed for all firms having the necessary items available in COMPUSTAT. We select only those firms for which $0<q_{2}<100$. For the selected firms, we compute industry I's average $q$ as:

$$
q_{2, a g g}=\frac{\sum_{i \in I} \text { firm_value }_{i}}{\sum_{i \in I} \text { DATA }_{i}}
$$

\section{A.3 Labor Reallocation}

We use data from the Bureau of Labor Statistics (BLS) Quarterly Census of Employment and Wages (QCEW) program 16 This program reports monthly employment and quarterly wages data at the SIC code level from 1975 to 2000, and at the NAICS code level from 1990 to 2005. Since there is no one-to-one correspondence between SIC and NAICS codes, we form industries at the 2-digit SIC code level that match industries at the 3-digit NAICS code level. We finally end up with 55 different industries, that match to only 47 different Compustat industries. We exclude the financial sector from our calculations. The employment data from the QCEW program is spliced in 1992.

We first compute the change in employment from month to month at the SIC and NAICS code level. If it is positive it is recorded as Job Creation, otherwise it corresponds to Job Destruction. We then

\footnotetext{
${ }^{16}$ Data are available at http://www.bls.gov/
} 
aggregate Job Creation, Job Destruction and Employment by quarter, and de-seasonalize each of these series separately using the X12-arima from the Census. Job Reallocation is then computed as the sum of Job Creation and Job Destruction, divided by Employment. Excess Job Reallocation is computed as the sum of Job Creation and Job Destruction minus the absolute change in Employment, divided by Employment.

\section{A.4 Managerial Wage Data from Current Population Survey}

We use the IPUMS-CPS data on respondents' annual wage earnings from 1971-2006. Managerial occupations are defined as follows: for 1971-82, (previous year) occupation codes 220-246 except 221 and 226; for 1983-1991, codes 003-019; for 1992-2002, codes 003-022; and codes 001-043 after 2002. We restrict the sample to managers who were over 21 years old, were employed in the private sector, and who were full-time workers in the previous year (i.e., they averaged at least 35 hours per week). We drop observations with annual earnings less than $\$ 2000$ in $1983 \$$. Finally, because wages are subject to top-coding, we follow Autor et al. (2007) and multiply top-codes by 1.5 (this adjustment only affects the reported standard deviations, not the IQR or IDR). The final sample size is about 3000 managers in the 1970s and grows to around 6000 managers in the 2000s.

\section{A.5 Managerial Wage Data from Execucomp}

We use the Compustat Executive Compensation (Execucomp) data, which contains annual compensation for top executives of over 2500 companies from 1992 to 2005, to compute the dispersion in managerial pay within industries. Compensation is measured using Execucomp's "tdc1" and "tdc2" variables. Both are the sum of the manager's salary, bonus, restricted stock grants, LTIP payouts, all other annual payments, and value of options. The difference between the two compensation measures is in what they use for the last term in the sum. Tdc1 uses the value of options grants, while tdc2 uses the value of options exercised. We compute the standard deviation of the logs of these two compensation measures within each industryyear in our data. This is then matched to our dataset on industries' Tobin's q and intangible ratios. We are left with a total of 644 observations (46 industries over 14 years).

\section{B Steady-State Growth Path}

Definition 1. A steady-state growth path is defined as a path for which aggregate establishment productivity $\left\{\bar{A}_{t}\right\}$ and the productivity of the newest vintage $\left\{\theta_{t}\right\}$ grow at a constant rate $g_{\theta}$, the variables $\left\{r_{t}, R_{t}, N_{t}\right\}$ are constant, the economy-wide productivity-level grows at a constant rate $g_{z}$, and all aggregate variables $\left\{Y_{t}, K_{t}, W_{t}, S_{t}, C_{t}, D_{t}, V_{t}^{a}\right\}$ grow at a constant rate

$$
g=\left(\left(1+g_{z}\right)\left(1+g_{\theta}\right)^{1-\nu}\right)^{\frac{1}{1-\alpha \nu}} .
$$


Along the steady-state growth path, the measure over establishment productivity and promised utilities satisfies:

$$
\Psi_{t+1, s+1}(A, v)=\Psi_{t, s}\left(\frac{A}{1+g_{\theta}}, v\right),
$$

the measure of active establishments satisfies:

$$
\lambda_{t+1, s}(A, v)=\lambda_{t, s}\left(\frac{A}{1+g_{\theta}}, v\right)
$$

and the value of an establishment of vintage s evolves according to:

$$
V_{t+1}(A, v ; s+1)=(1+g) V_{t}\left(\frac{A}{1+g_{\theta}}, v(1+g)^{1-\gamma}, s\right)
$$

To construct the steady-state growth path, we normalize variables in efficiency units. This allows us to restate the production technology as follows :

$$
\widetilde{y}_{t}=\widetilde{k}_{t}^{\alpha \nu}
$$

where a variable with a tilde, $\widetilde{x}_{t}$, denotes the variable, $x$, expressed in per capita terms and in adjusted efficiency units of the latest vintage (blueprint):

$$
\widetilde{x}_{t}=\frac{x_{t}}{z_{t}^{\frac{1}{1-\alpha \nu}} \theta_{t}^{\frac{1-\nu}{1-\alpha \nu}}} .
$$

We have normalized the population $L$ to one.

As noted in the main text, we normalize productivity by the blueprint level of technology, and denote the normalized variables with a hat: $\widehat{A}_{t}=A_{t} / \theta_{t}$. By construction, $\widehat{A} \geq 1$ for a new establishment (vintage zero). The organizational capital of existing establishments in the new efficiency units shrinks at a rate $\left(1+g_{\theta}\right)$. See equation (2.13). This notation allows us to reformulate the optimal contract along the steady-state growth path.

The owner maximizes his value $\widehat{V}(\widehat{A}, \widetilde{v})$ by optimally choosing current compensation $\widetilde{c}$ and future promised utilities $\widetilde{v}^{\prime}(\cdot)$ :

$$
\widetilde{V}(\widehat{A}, \widetilde{v})=\max [\widehat{V}(\widehat{A}, \widetilde{v}), 0]
$$

and

$$
\widehat{V}(\widehat{A}, \widetilde{v})=\max _{\widetilde{c}, \widetilde{v}^{\prime}(\cdot)}\left[\begin{array}{c}
\widetilde{y}-\widetilde{W}-R \widetilde{k}-\widetilde{c} \\
+e^{-\left(\rho_{o}-(1-\gamma) \widehat{g}\right)} \int \widetilde{V}\left(\widehat{A}^{\prime}, \widetilde{v}^{\prime}\right) \Gamma\left(\varepsilon^{\prime}\right) d \varepsilon^{\prime},
\end{array}\right]
$$

subject to the law of motion for organizational capital in (2.13), the promise keeping constraint

$$
\widetilde{v}=u(\widetilde{c})+e^{-\left(\rho_{m}-(1-\gamma) \widehat{g}\right)}\left[\int \beta_{s^{\prime}}\left(\widetilde{v}, \varepsilon^{\prime}\right) \widetilde{v}^{\prime}\left(\widehat{A}^{\prime}\right) \Gamma\left(\varepsilon^{\prime}\right) d \varepsilon^{\prime}+\widetilde{\omega}\left(\widehat{A}^{\prime}\right) \int\left(1-\beta\left(\widetilde{v}, \varepsilon^{\prime}\right)\right) \Gamma\left(\varepsilon^{\prime}\right) d \varepsilon^{\prime}\right]
$$


and subject to participation constraints for all $\widehat{A}^{\prime}$ :

$$
\widetilde{v}^{\prime}\left(\widehat{A}^{\prime}\right) \geq \widetilde{\omega}\left(\widehat{A}^{\prime}\right)
$$

The indicator variable $\beta$ is one if continuation is optimal and zero elsewhere:

$$
\begin{aligned}
& \beta=1 \text { if } \widetilde{v}^{\prime}\left(\widehat{A}^{\prime}\right) \leq \widetilde{v}^{*}\left(\widehat{A}^{\prime}\right) \\
& \beta=0 \text { elsewhere }
\end{aligned}
$$

The outside option process is determined in equilibrium by the zero-profit condition for new entrants:

$$
\widehat{V}(\max (\widehat{A} \phi, 1), \omega(\widehat{A}))=S
$$

Equation (B.2) implies that the outside option $\omega\left(\widehat{A}_{t}\right)$ is constant in the range $A \in\left[0, \phi^{-1}\right]$. We refer to this range as the insensitivity region, because the outside option does not depend on the organizational capital accumulated in the current establishment. When the fraction of capital $\phi$ that is portable is zero, the outside option is constant for all $A>0$.

\section{Proof of Proposition 3.1}

Proof. The first-order condition implies that compensation $\widetilde{c}$ is constant as long as the participation constraint does not bind. When a new match is formed, the normalized promised utility $\widetilde{v}$ starts off at $\widetilde{v}_{0}=\omega\left(\widehat{A}_{t}\right)$. The dynamics of the optimal wage contract can be characterized by setting up the Lagrangian. Let $\mu$ denote the multiplier on the promised utility constraint and let $\lambda\left(\widehat{A}^{\prime}\right)$ denote the multiplier on the participation constraint in state $\widehat{A}^{\prime}$. We assume $\widehat{V}(\cdot)$ is strictly concave and twice continuously differentiable. When the participation constraint $\widehat{A}^{\prime}$ does not bind $\left(\lambda\left(\widehat{A}^{\prime}\right)=0\right)$, conditional on continuation of the relationship $(\beta=1)$, the law of motion for the promised utility in efficiency units $\widetilde{v}$ satisfies the first order condition:

$$
\mu=\frac{-\partial \widehat{V}\left(\widehat{A}^{\prime}, \widetilde{v}^{\prime}\right)}{\partial \widetilde{v}^{\prime}}
$$

The left hand side is the cost to the owner of increasing the manager's compensation today. It equals $\mu$, the shadow price of a dollar today, from the envelope condition. From the first order condition for consumption we know that $\mu=1 / u_{c}(\widetilde{c})$. The right-hand side is the cost of increasing the manager's compensation tomorrow, from the first-order condition for $\widetilde{v}^{\prime}$. From the envelope condition, this equals $\mu^{\prime}=1 / u_{c}\left(\widetilde{c}^{\prime}\right)$. So, the first order condition implies that consumption $\widetilde{c}$ must be constant over time, as long as the manager's participation constraint does not bind. As a result, actual managerial compensation $c$ grows at the rate of output growth $g$ on the steady-state growth path. When the participation constraint does bind, the following inequality obtains:

$$
\mu<\frac{-\partial \widehat{V}\left(\widehat{A}^{\prime}, \widetilde{v}^{\prime}\right)}{\partial \widetilde{v}^{\prime}}
$$


The utility cost of increasing the manager's compensation to the owner increases. From the concavity of $u(\cdot)$, it follows that the manager's promised utility and current compensation (in efficiency units) increase when the participation constraint binds. When the constraint does bind, we increase $\widetilde{c}$ to make sure the constraint holds with equality. This is optimal (see Kuhn-Tucker conditions).

This suggests a simple consumption rule is optimal. We conjecture the optimal consumption function $C(\widetilde{v}, \widehat{A})$ such that:

$$
C(\widetilde{v}, \widehat{A})=u_{c}^{-1}(1 / \mu)
$$

where $\mu=\frac{-\partial \widehat{V}(\widehat{A}, \widetilde{v})}{\partial \widetilde{v}}$. Define the running maximum of $\widehat{A}$ as $\widehat{A}_{\text {max }, t}=\max \left\{\widehat{A}_{\tau}, \tau \leq t\right\}$. In addition, let $T$ denote the random stopping time when the match gets terminated because of zero surplus:

$$
T=\inf \left\{\tau \geq 0: \widehat{V}\left(\widehat{A}_{\tau}, \widetilde{v}_{\tau}\right)=0\right\}
$$

Compensation is determined by the running maximum of productivity for all $0<t<T$ :

$$
c_{t}=c\left(\widehat{A}_{\max , t}\right)=\max \left\{c_{0}, C\left(\omega\left(\widehat{A}_{\max , t}\right), \widehat{A}_{\max , t}\right)\right\}
$$

This consumption function satisfies the necessary and sufficient Kuhn-Tucker conditions if the continuation probability $\beta$ is non-increasing in $\widehat{A}$. This being the case, the participation constraint only binds if $\widehat{A}$ exceeds it previous maximum. It is easy to verify that $\beta$ is indeed non-increasing in $\widehat{A}$ given this consumption function.

\section{Proof of Proposition 3.2}

Proof. The discount rate wedge induces a downward drift in the manager's consumption and promised utility. When the participation constraint does not bind, the envelope condition and the first order condition for $\widetilde{v}^{\prime}$ imply the following:

$$
\frac{-\partial \widehat{V}(\widehat{A}, \widetilde{v})}{\partial \widetilde{v}}=\mu=e^{\left(\rho_{m}-\rho_{o}\right)} \frac{-\partial \widehat{V}\left(\widehat{A}^{\prime}, \widetilde{v}^{\prime \prime}\right)}{\partial \widetilde{v}^{\prime}}
$$

Because $e^{\rho_{m}-\rho_{o}}>1$, the owner's utility cost of providing compensation tomorrow is lower than $\mu$, the cost today. As a result, the optimal promised utility is decreasing over time. Because $\mu=u_{c}^{-1}(\widetilde{c})$, this also implies that current consumption drifts down. By construction, this consumption policy satisfies the necessary and sufficient first order conditions for optimality.

\section{Transition Experiment}

Definition 2. A constant-discount rate transition between two steady state growth paths is defined as a path for which the productivity of the newest vintage grows at rate $g_{t, \theta}$, the economy-wide productivity-level 
grows at a rate $g_{z, t}$, and all aggregate variables $\left\{Y_{t}, K_{t}, w_{t}, C_{t}\right\}_{t=0, T}$ have a constant trend growth rate

$$
g=\left(\left(1+g_{z}\right)\left(1+g_{\theta}\right)^{1-\nu}\right)^{\frac{1}{1-\alpha \nu}}
$$

The rental rate on capital $R_{t}$ and the discount rate $r_{t}$ are constant. The measure over promised utilities and establishment productivity satisfies (2.10) and (2.11) during the transition. At $t=T$, this economy reaches its new steady-state growth path. So for $i>1$ :

$$
\begin{aligned}
& \Psi_{T+i, s}(A, v)=\Psi_{T+i-1, s}\left(\frac{A}{1+g_{\theta}}, v\right) \\
& \lambda_{T+i, s}(A, v)=\lambda_{T+i-1, s}\left(\frac{A}{1+g_{\theta}}, v\right) .
\end{aligned}
$$

Output deviates from its trend growth path during the transition because the average establishment productivity level deviates from its initial steady-state growth path $\left\{\bar{A}_{\text {old }, t}\right\}$. The average productivity levels changes, because the joint measure over establishment-specific productivity and promised utility is changing. Along the transition path, we check that the rental rate for physical capital is constant:

$$
R_{t}=\alpha v \widetilde{K}_{n e w, t}^{\alpha \nu-1}=\alpha v\left(\widetilde{K}_{o l d, t}\right)^{\alpha \nu-1}
$$

where $\widetilde{K}_{t}=\frac{K_{t}}{\bar{A}_{t}^{\frac{1-\nu}{1-\alpha v}} z_{t}^{1-\alpha \nu}}$ denotes the capital stock in adjusted efficiency units. The aggregate capital stock is adjusted such that

$$
\varphi_{t}=\frac{\widehat{K}_{n e w, t}}{\widehat{K}_{o l d, t}}=\left(\frac{\bar{A}_{n e w, t}}{\bar{A}_{o l d, t}}\right)^{\frac{1-\nu}{1-\alpha v}}
$$

Capital is supplied perfectly elastically at a constant interest rate. Along the transition path, all aggregate variables $\left\{Y_{\text {new }, t}, K_{\text {new }, t}, W_{\text {new }, t}, C_{n e w, t}\right\}_{t=0, T}$ are scaled up by $\varphi_{t}$. This is the productivity adjustment relative to the old steady-state growth path. Once we have computed $\left\{\varphi_{t}\right\}$, we can back out the transition path for all the other variables.

Reverse Shooting Algorithm The objective is to compute the transition for the value function, aggregate productivity, the outside option function and the joint measure over promised consumption and productivity $\left\{V_{t}, \bar{A}_{t}, \omega_{t}, \Psi_{t, s}, \lambda_{t, s}\right\}$. We start in the new steady state with the new vintage-specific growth rate $g_{\theta, T}$ at $T$, and the "stationary" joint measure $\Psi_{T, s}$ over organizational capital and promised consumption, which satisfy the conditions in equation (C.2). We conjecture a $\left\{\varphi_{t}\right\}_{t=0}^{T}$ sequence. Because we know $\widehat{V}_{T}$, the owner's value of an establishment at the beginning of period $t$ can be constructed recursively, starting in $i=1$ :

$$
\widehat{V}_{T-i}(\widehat{A}, \widetilde{v} ; s)=\max _{\widetilde{c} \widetilde{v}_{t}^{\prime}(\cdot)}\left[\begin{array}{c}
\widetilde{y}_{T-i+1}-W-R \widetilde{k}_{T-i+1}-\widetilde{c}_{T-i+1} \\
+R^{-1}(1+g) \int \widetilde{V}_{T-i+1}\left(\widehat{A}^{\prime}, \widetilde{v}^{\prime} ; s+1\right) Q_{s^{\prime}}\left(\varepsilon^{\prime}\right) d \varepsilon^{\prime}
\end{array}\right]
$$


subject to the law of motion for capital in (2.13), the promised consumption constraint in (B.1), and a series of participation constraints:

$$
\widetilde{v}^{\prime} \geq \widetilde{\omega}_{T-i+1}\left(A^{\prime}\right)
$$

and, finally, the value of the firm is defined as:

$$
\widetilde{V}_{T-i}(\widehat{A}, \widetilde{v})=\max \left[\widehat{V}_{T-i}(\widehat{A}, \widetilde{v}), 0\right] .
$$

We solve for $\left\{V_{t}, \bar{A}_{t}, \omega_{t}, \Psi_{t, s}, \lambda_{t, s}\right\}_{t=1}^{T}$ starting in the last period $T$.

Simulating Forward Next, we simulate this economy forward, starting at the initial values for $\left(V_{0}, \bar{A}_{0}, \omega_{0}, \Psi_{0, s}, \lambda_{0, s}\right)$ in the old steady-state growth path, using our solution for the transition path $\left\{V_{t}, \bar{A}_{t}, \omega_{t}, \Psi_{t, s}, \lambda_{t, s}\right\}_{t=1}^{T}$. We use a sample of $N=5000$ establishments. This gives us a new guess for the aggregate establishment productivity series and hence for $\left\{\varphi_{t}^{\prime}\right\}_{t=0}^{T}$. We continue iterating until we achieve convergence.

\section{Calibration Details}

To calibrate the depreciation rate, the tax rate and the capital share $\alpha \nu$, we used mostly NIPA data. Let $C F C$ denote the consumption of fixed capital. Let $K_{I N V}$ denote the stock of inventories, obtained from NIPA Table 5.7.5B. (Private Inventories and Domestic Final Sales by Industry). Let $K_{E S}$ denote fixed assets, obtained from NIPA Table 6.1. (Current-Cost Net Stock of Private Fixed Assets by Industry Group and Legal Form of Organization). The depreciation rate is computed as

$$
\delta=C F C /\left(K_{E S}+K_{I N V}\right) .
$$

The average tax rate $\tau_{c}$ is computed as follows. Let $C T$ denote corporate taxes, let $N P$ denote net product, let $S T$ denote Sales Taxes, and let $S L P T R$ denote state and local taxes. The tax rate is computed as

$$
\tau_{c}=C T /(N P-C E-S T),
$$

where we compute $S T$ as $C T-R A T I O \times S L P T R$ and $R A T I O$ is the average ratio of fixed assets held by non-farm, non-financial corporations to total fixed assets.

To compute the average cost of capital $r$, we computed the weighted-average of the average return on equity and the average return on corporate bonds over the period 1950-2005. The average return on corporate bonds was computed using the Dow Jones corporate bond index 17 . The average return on equity is computed from the log price/dividend ratio and a constant real growth rate for dividends of $1.8 \%$, the average growth rate over the sample 18 The dividend series and the price/dividend ratio from

\footnotetext{
${ }^{17}$ Data are available at http://www.globalfinancialdata.com

${ }^{18}$ Data are available at http://wrds.wharton. upenn.edu
} 
CRSP are adjusted for repurchases. The weights in the average are based on the aggregate market value of equity and corporate bonds. The resulting average cost of capital is $5.5 \%$. 
Table I: Benchmark Calibration

\begin{tabular}{|c|c|c|}
\hline Parameter & $\overline{\text { Value }}$ & Source \\
\hline $\begin{array}{l}\nu \\
\delta \\
\alpha \\
r\end{array}$ & $\begin{array}{l}.75 \\
.06 \\
.30 \\
.055\end{array}$ & $\begin{array}{c}\text { Atkeson and Kehoe (2005) } \\
\text { NIPA } \\
K / Y=1.77 \\
\text { FoF, CRSP,DJCBI }\end{array}$ \\
\hline $\begin{array}{l}\rho_{o} \\
\rho_{o} \\
\gamma \\
g\end{array}$ & $\begin{array}{l}.02 \\
.03 \\
1.6 \\
.022\end{array}$ & $\begin{array}{c}\text { equation (2.8) } \\
\text { NIPA }\end{array}$ \\
\hline $\begin{array}{l}m_{s} \\
\sigma_{s} \\
S \\
\phi\end{array}$ & $\begin{array}{c}0 \\
19 \% \text { exc. reall. rate } \\
4.3 \% \text { exit rate } \\
0.5\end{array}$ & $\begin{array}{c}\text { job reallocation - QCEW } B L S \\
\text { entry and exit } \\
\text { wage inequality - QCEW BLS }\end{array}$ \\
\hline
\end{tabular}

Notes: This Table lists our benchmark parameter choices. Section 4.2 justifies these choices and Appendix D provides more details on the data we used. NIPA stands for National Income and Products Accounts, CRSP for Center for Research in Securities Prices, DJCBI for Dow Jones Corporate Bond Index, QCEW stands for Quarterly Census of Employment and Wages, and BLS for Bureau of Labor Statistics. The abbreviation "exc. reall. rate" stands for excess reallocation rate in the initial steady state. 
Table II: Main Results-Benchmark Calibration

\begin{tabular}{|c|c|c|c|c|c|c|c|c|c|c|c|}
\hline & \multicolumn{3}{|c|}{ Log Compensation } & \multicolumn{3}{|c|}{ Log Productivity } & \multicolumn{5}{|c|}{ Aggregates } \\
\hline & Std & $I Q R$ & $I D R$ & Std & $I Q R$ & $I D R$ & $E R E A L L$ & EXIT & Tobin's q & $\frac{V}{\left(Y-S^{a}\right)}$ & $\frac{M}{\left(Y-S^{a}\right)}$ \\
\hline before & 0.94 & 0.01 & 0.08 & 10.69 & 18.27 & 29.16 & 18.96 & 4.33 & 1.40 & 0.83 & 8.27 \\
\hline $1971-1975$ & 1.48 & 0.01 & 0.09 & 10.80 & 18.32 & 28.99 & 17.83 & 7.74 & 1.40 & 0.83 & 8.04 \\
\hline $1976-1980$ & 1.24 & 0.01 & 0.08 & 11.00 & 18.25 & 29.13 & 16.62 & 6.65 & 1.43 & 0.89 & 7.88 \\
\hline $1981-1985$ & 1.75 & 0.01 & 0.10 & 11.09 & 18.42 & 29.38 & 15.30 & 5.62 & 1.46 & 0.93 & 7.72 \\
\hline $1986-1990$ & 2.31 & 0.02 & 0.11 & 11.26 & 18.32 & 29.80 & 13.52 & 4.08 & 1.50 & 1.00 & 7.51 \\
\hline 1991-1995 & 4.34 & 0.03 & 0.13 & 11.67 & 18.43 & 30.76 & 12.87 & 3.56 & 1.54 & 1.07 & 7.37 \\
\hline 1996-2000 & 6.41 & 0.09 & 11.77 & 11.79 & 18.05 & 30.84 & 12.70 & 3.53 & 1.56 & 1.12 & 7.29 \\
\hline 2001-2005 & 8.22 & 0.13 & 9.73 & 12.22 & 18.36 & 31.78 & 12.26 & 3.05 & 1.59 & 1.18 & 7.22 \\
\hline 2006-2010 & 11.03 & 8.63 & 8.94 & 12.58 & 18.53 & 32.58 & 12.02 & 2.94 & 1.62 & 1.23 & 7.17 \\
\hline 2011-2015 & 12.78 & 8.82 & 21.47 & 12.57 & 18.50 & 32.52 & 11.90 & 2.84 & 1.62 & 1.22 & 7.11 \\
\hline after & 26.98 & 0.09 & 35.07 & 15.36 & 21.14 & 38.98 & 11.35 & 1.20 & 1.64 & 1.26 & 6.47 \\
\hline
\end{tabular}

Notes: The panel on the left reports the cross-sectional standard deviation (Std), inter-quartile range (IQR) and the inter-decile range (IDR) for log compensation $\log \widetilde{c}$ and $\log$ productivity $(1-\nu) \log \widehat{A}$ in percentage points. The panel on the right reports the excess job reallocation rate (EREALL), the entry/exit rate (EXIT), Tobin's q, the ratio of aggregate firm value to output $\left(V /\left(Y-S^{a}\right)\right)$, and the ratio of managerial wealth to output $\left(M /\left(Y-S^{a}\right)\right)$. The economy transitions from high vintage-specific growth $g_{\theta, 0}$ before 1971 to low vintage-specific growth $g_{\theta, T}$ after 1971 . The transition takes place over $T=20$ years. The results are for the benchmark parameters. 
Table III: Compensation Sensitivity in Large Firms-Benchmark Calibration

\begin{tabular}{c|cccc|cccc|}
\hline \hline & \multicolumn{4}{|c|}{ Top 500 } & \multicolumn{4}{c|}{ Top 50 } \\
\hline & $\Delta c / \Delta A$ & $S t d$ & $I Q R$ & $I D R$ & $\Delta c / \Delta A$ & $S t d$ & $I Q R$ & $I D R$ \\
\hline $1971-1975$ & -1.68 & 3.76 & 0.20 & 3.51 & 3.35 & 8.99 & 0.39 & 0.86 \\
$1976-1980$ & 0.14 & 3.55 & 0.27 & 0.53 & 1.08 & 10.83 & 0.57 & 4.79 \\
$1981-1985$ & 0.48 & 4.86 & 0.41 & 0.61 & 6.59 & 13.71 & 1.95 & 27.05 \\
$1986-1990$ & 1.03 & 6.98 & 0.43 & 0.65 & 15.87 & 16.80 & 12.83 & 36.25 \\
$1991-1995$ & 1.76 & 10.36 & 0.49 & 3.77 & 18.86 & 22.19 & 28.02 & 52.99 \\
$1996-2000$ & 3.72 & 13.90 & 0.49 & 25.14 & 37.58 & 23.88 & 28.30 & 54.81 \\
2001-2005 & 6.08 & 19.22 & 2.41 & 39.25 & 53.67 & 25.07 & 31.83 & 54.92 \\
2006-2010 & 5.86 & 24.12 & 11.18 & 52.04 & 49.89 & 28.03 & 32.85 & 62.17 \\
2011-2015 & 8.72 & 29.04 & 20.97 & 66.64 & 46.63 & 31.11 & 37.41 & 86.63 \\
\hline \hline
\end{tabular}

Notes: This table reports the sensitivity of compensation to size, the cross-sectional standard deviation (Std), inter-quartile range (IQR) and the inter-decile range (IDR) for $\log$ compensation $\log \widetilde{c}$ for the 500 and 50 largest establishments. The economy transitions from high vintage-specific growth $g_{\theta, 0}$ before 1971 to low vintage-specific growth $g_{\theta, T}$ after 1971. The transition takes place over $T=20$ years. The table reports the ratio of market value of the establishment to the aggregate capital stock, at different percentiles of the cross-sectional market value distribution. The results are for the benchmark parameters. 
Table IV: Robustness: Compensation and Productivity

\begin{tabular}{|c|c|c|c|c|c|c|c|c|c|c|c|c|}
\hline & \multicolumn{6}{|c|}{ No Portability } & \multicolumn{6}{|c|}{ High Portability } \\
\hline & \multicolumn{3}{|c|}{ Log Compensation } & \multicolumn{3}{|c|}{ Log Productivity } & \multicolumn{3}{|c|}{ Log Compensation } & \multicolumn{3}{|c|}{ Log Productivity } \\
\hline & $S t d$ & $I Q R$ & $I D R$ & Std & $I Q R$ & $I D R$ & $S t d$ & $I Q R$ & $I D R$ & $S t d$ & $I Q R$ & $I D R$ \\
\hline before & 0.00 & 0.00 & 0.00 & 10.77 & 18.52 & 29.45 & 9.61 & 0.46 & 5.24 & 13.73 & 23.33 & 38.51 \\
\hline $1971-1975$ & 0.02 & 0.00 & 0.00 & 10.06 & 17.46 & 26.41 & 14.79 & 0.51 & 19.54 & 13.63 & 23.57 & 37.50 \\
\hline $19^{r} 6-1980$ & 0.00 & 0.00 & 0.00 & 9.49 & 15.85 & 24.67 & 12.74 & 5.47 & 16.50 & 13.87 & 23.61 & 37.62 \\
\hline $1981-1985$ & 0.00 & 0.00 & 0.00 & 9.33 & 15.12 & 24.46 & 13.52 & 10.74 & 14.46 & 14.17 & 23.58 & 38.09 \\
\hline 1986-1990 & 1.12 & 0.00 & 0.00 & 9.41 & 14.87 & 24.54 & 14.99 & 8.60 & 16.32 & 14.47 & 23.48 & 38.50 \\
\hline 1991-1995 & 2.00 & 0.00 & 4.86 & 9.72 & 14.24 & 25.50 & 19.57 & 8.27 & 19.30 & 14.84 & 23.88 & 38.98 \\
\hline $1996-2000$ & 3.18 & 1.83 & 6.50 & 10.08 & 14.38 & 26.34 & 23.21 & 8.29 & 36.65 & 15.14 & 24.04 & 39.55 \\
\hline 2001-2005 & 3.46 & 4.57 & 8.07 & 10.50 & 14.64 & 27.21 & 25.68 & 8.37 & 49.22 & 15.60 & 24.20 & 41.01 \\
\hline 2006-2010 & 4.27 & 6.43 & 8.70 & 10.99 & 15.17 & 28.34 & 29.12 & 8.69 & 53.04 & 16.07 & 24.75 & 42.01 \\
\hline 2011-2015 & 4.47 & 7.68 & 11.41 & 11.31 & 15.54 & 28.74 & 31.32 & 9.29 & 56.28 & 16.52 & 25.27 & 43.21 \\
\hline after & 0.00 & 0.00 & 0.00 & 13.43 & 16.81 & 33.17 & 48.56 & 29.45 & 98.49 & 21.19 & 32.19 & 55.35 \\
\hline
\end{tabular}

Notes: The panel on the left shows results for $\phi=0$ (no portability). The panel on the right shows results for $\phi=.75$ (high portability). The economy transitions from high vintage-specific growth $g_{\theta, 0}$ before 1971 to low vintage-specific growth $g_{\theta, T}$ after 1971 . The transition takes place over $T=20$ years. The table reports the cross-sectional standard deviation (Std), inter-quartile range (IQR) and the inter-decile range (IDR) for log compensation $\log \widetilde{c}$ and $\log$ productivity $(1-\nu) \log \widehat{A}$ in percentage points. The results are for the benchmark parameters. 
Table V: Robustness: Aggregate Variables

\begin{tabular}{|c|c|c|c|c|c|c|c|c|c|c|}
\hline & \multicolumn{5}{|c|}{ Low Portability } & \multicolumn{5}{|c|}{ High Portability } \\
\hline & (1) & $(2)$ & $(3)$ & $(4)$ & $(5)$ & (1) & (2) & (3) & (4) & (5) \\
\hline & $E R E A L L$ & EXIT & Tobin's q & $\frac{V}{\left(Y-S^{a}\right)}$ & $\frac{M}{\left(Y-S^{a}\right)}$ & $E R E A L L$ & $E X I T$ & Tobin's q & $\frac{V}{\left(Y-S^{a}\right)}$ & $\frac{M}{\left(Y-S^{a}\right)}$ \\
\hline before & 18.93 & 4.32 & 1.36 & 0.74 & 6.02 & 17.67 & 3.40 & 1.37 & 0.76 & 4.99 \\
\hline $1971-1975$ & 21.78 & 11.68 & 1.38 & 0.82 & 7.61 & 18.03 & 7.14 & 1.35 & 0.72 & 4.48 \\
\hline $19^{7} 6-1980$ & 18.49 & 9.07 & 1.43 & 0.89 & 7.59 & 14.94 & 4.70 & 1.38 & 0.76 & 4.54 \\
\hline 1981-1985 & 16.26 & 7.06 & 1.49 & 1.01 & 7.51 & 14.37 & 4.33 & 1.40 & 0.80 & 4.61 \\
\hline 1986-1990 & 14.59 & 5.67 & 1.58 & 1.16 & 7.42 & 12.15 & 2.46 & 1.44 & 0.86 & 4.58 \\
\hline 1991-1995 & 13.20 & 4.29 & 1.66 & 1.32 & 7.24 & 12.27 & 2.52 & 1.45 & 0.88 & 4.59 \\
\hline 1996-2000 & 12.64 & 3.85 & 1.72 & 1.43 & 7.12 & 11.86 & 2.40 & 1.46 & 0.91 & 4.54 \\
\hline 2001-2005 & 11.92 & 3.03 & 1.77 & 1.52 & 6.97 & 11.32 & 1.74 & 1.47 & 0.92 & 4.49 \\
\hline 2006-2010 & 12.05 & 3.22 & 1.81 & 1.60 & 6.92 & 11.63 & 2.21 & 1.47 & 0.92 & 4.50 \\
\hline 2011-2015 & 11.87 & 2.98 & 1.84 & 1.66 & 6.84 & 10.75 & 1.36 & 1.48 & 0.93 & 4.46 \\
\hline after & 11.50 & 1.48 & 2.11 & 2.19 & 5.77 & 11.24 & 0.84 & 1.45 & 0.89 & 4.09 \\
\hline
\end{tabular}

Notes: The panel on the left shows results for $\phi=0$ (low portability). The panel on the right shows results for $\phi=.75$ (high portability). The economy transitions from high vintage-specific growth $g_{\theta, 0}$ before 1971 to low vintage-specific growth $g_{\theta, T}$ after 1971 . The transition takes place over $T=20$ years. The table reports the excess job reallocation rate (EREALL), the entry/exit rate (EXIT), Tobin's q, the ratio of aggregate firm value to output $\left(V /\left(Y-S^{a}\right)\right)$, and the ratio of managerial wealth to output $\left(M /\left(Y-S^{a}\right)\right)$. The results are for the benchmark parameters. 
Table VI: Increasing Wage Dispersion

\begin{tabular}{l|ccc}
\hline \hline & Std & $I Q R$ & $I D R$ \\
\hline & \multicolumn{3}{|c}{ Panel A: All Workers } \\
1975-1979 & 21.4 & 29.1 & 53.2 \\
1980-1984 & 22.9 & 29.3 & 57.2 \\
1985-1989 & 24.2 & 30.8 & 58.5 \\
1990-1994 & 25.1 & 31.6 & 61.1 \\
1995-1999 & 26.9 & 32.8 & 65.7 \\
2000-2004 & 28.7 & 34.5 & 67.9 \\
\hline & \multicolumn{3}{|c}{ Panel B: All Managers } \\
1975-1979 & 59.4 & 72.9 & 140.8 \\
1980-1984 & 61.3 & 79.8 & 147.5 \\
1985-1989 & 62.9 & 82.5 & 152.7 \\
1990-1994 & 64.8 & 83.8 & 156.6 \\
1995-1999 & 67.2 & 83.3 & 157.7 \\
2000-2004 & 68.8 & 84.2 & 160.4 \\
\hline & \multicolumn{3}{|c}{ Panel C: Top-3 Managers } \\
1975-1979 & 55.7 & 74.1 & 135.1 \\
1980-1984 & 58.3 & 74.0 & 146.7 \\
1985-1989 & 69.7 & 90.2 & 172.6 \\
1990-1994 & 76.9 & 100.0 & 186.8 \\
1995-1999 & 92.6 & 124.0 & 231.7 \\
2000-2004 & 99.4 & 149.5 & 260.9 \\
\hline \hline
\end{tabular}

Notes: All three panels plot the cross-sectional standard deviation, inter-quartile range, and inter-decile range of log wages. Statistics are averaged over 5-year periods. In Panel A, we measure intra-industry, between-establishment wage inequality. The data are from the Quarterly Census of Employment and Wages (QCEW) collected by the Bureau of Labor Statistics (BLS). The unit of observation is an establishment, for which we know the average wage. We calculate the within-industry wage dispersion from a panel of 55 2-digit SIC-code industries, and average across industries. In Panel B, we use individual-level data from the Current Population Survey, March issue. We select only the managerial occupations. Finally, Panel C uses data from Frydman and Saks (2006) for the three highest-paid officers in the largest 50 firms in 1960 and 1990. 


\section{Table VII: Valuation Ratios for US Corporate Sector}

\begin{tabular}{l|cc}
\hline \hline & $(1)$ & $(2)$ \\
& Tobin's $q$ & $V /\left(Y-S^{a}\right)$ \\
\hline 1965-1969 & 1.96 & 1.80 \\
1970-1974 & 1.49 & 1.54 \\
$1975-1979$ & 0.97 & 1.13 \\
1980-1984 & 0.94 & 1.16 \\
1985-1989 & 1.33 & 1.49 \\
1990-1994 & 1.70 & 1.82 \\
1995-1999 & 2.58 & 2.53 \\
2000-2004 & 2.33 & 2.41 \\
2005-2008.I & 2.04 & 2.19 \\
\hline \hline
\end{tabular}

Notes: Tobin's q is the ratio of the market value of US corporations $V^{a}$ divided by the replacement cost of the physical capital stock $K$. The value-output ratio $\left(V /\left(Y-S^{a}\right)\right)$ is the market value of US corporations $V^{a}$ divided by value-added $Y-S^{a}$ of the non-financial corporate sector.

Table VIII: Cross-sectional Results: Tobin's q and Establishment-Level Wage Dispersion

\begin{tabular}{lllll}
\hline \hline & $(1)$ & $(2)$ & $(3)$ & $(4)$ \\
Constant & -0.401 & -0.341 & 0.232 & 0.264 \\
& $(0.296)$ & $(0.293)$ & $(0.187)^{* * *}$ & $(0.185)^{* * *}$ \\
INTAN & & 0.117 & & 0.086 \\
& & $(0.167)$ & & $(0.105)$ \\
WDISP & 1.113 & 1.131 & 0.789 & 0.801 \\
& $(0.196)^{* * *}$ & $(0.194)^{* * *}$ & $(0.123)^{* * *}$ & $(0.122)^{* * *}$ \\
WDISP* INTAN & & -0.275 & & -0.174 \\
& & $(0.129)^{* *}$ & & $(0.064)^{*}$ \\
$\Delta$ Tobin q / $\Delta$ WDISP & & 0.981 & 0.706 \\
& & $(0.199)^{* * *}$ & $(0.125)^{* * *}$ \\
\hline Number of Industries & \multicolumn{3}{c}{2632} \\
Observations & \multicolumn{3}{c}{} \\
\hline \hline
\end{tabular}

Notes: $*$ significant at $10 \%$; $* *$ significant at $5 \%$; ** significant at $1 \%$. This table reports fixed effects estimates of Tobin q1 and Tobin q2 on wage dispersion (WDISP) for the periods 1992-2005. Wage dispersion is measured as the cross-sectional standard deviation of log wages across establishments within an industry. The regressions include year and industry fixed effects. The definition of these variables is detailed in Appendix A.2. Robust standard errors are shown in parentheses. 
Table IX: Cross-sectional Results: Tobin's q and Executive Wage Dispersion

\begin{tabular}{lllll}
\hline \hline & $(1)$ & $(2)$ & $(3)$ & $(4)$ \\
Constant & 0.627 & 0.750 & 1.039 & 1.117 \\
& $(0.163)^{* * *}$ & $(0.175)^{* * *}$ & $(0.101)^{* * *}$ & $(0.104)^{* * *}$ \\
INTAN & & -0.453 & & -0.276 \\
& & $(0.103)^{* * *}$ & & $(0.066)^{* * *}$ \\
WDISP & 0.765 & 0.756 & 0.469 & 0.459 \\
& $(0.174)^{* * *}$ & $(0.184)^{* * *}$ & $(0.108)^{* * *}$ & $(0.112)^{* * *}$ \\
WDISP* INTAN & & 0.122 & & 0.077 \\
& $(0.061)^{* *}$ & & $(0.045)^{*}$ \\
$\Delta$ Tobin q / $\Delta$ WDISP & & 0.823 & 0.502 \\
& & $(0.172)^{* * *}$ & $(0.105)^{* * *}$ \\
\hline Number of Industries & \multicolumn{3}{c}{64} \\
Observations & \multicolumn{3}{c}{64} \\
\hline \hline
\end{tabular}

Notes: * significant at $10 \%$; $*$ significant at $5 \%$; ** significant at $1 \%$. This table reports fixed effects estimates of Tobin q1 and Tobin q2 on wage dispersion (WDISP) for the periods 1992-2005. Wage dispersion is measured as the cross-sectional standard deviation of log wages across individual executives within an industry. Wages are the sum of the manager's salary, bonus, restricted stock grants, LTIP payouts, all other annual payments, and value of options granted ("tdc1"). The regressions include year and industry fixed effects. Further detail on the data is in Appendix A.2 and A.5. Robust standard errors are shown in parentheses. 


\section{Figure 1: Optimal Compensation and Size}

This figure plots the running maximum of productivity on the horizontal axis, $\widehat{A}_{\text {max }, t}$ against current productivity, $\widehat{A}_{t}$, on the vertical axis. It considers the case in which managers and owners share the same rate of time preference $\rho_{m}=\rho_{o}$.

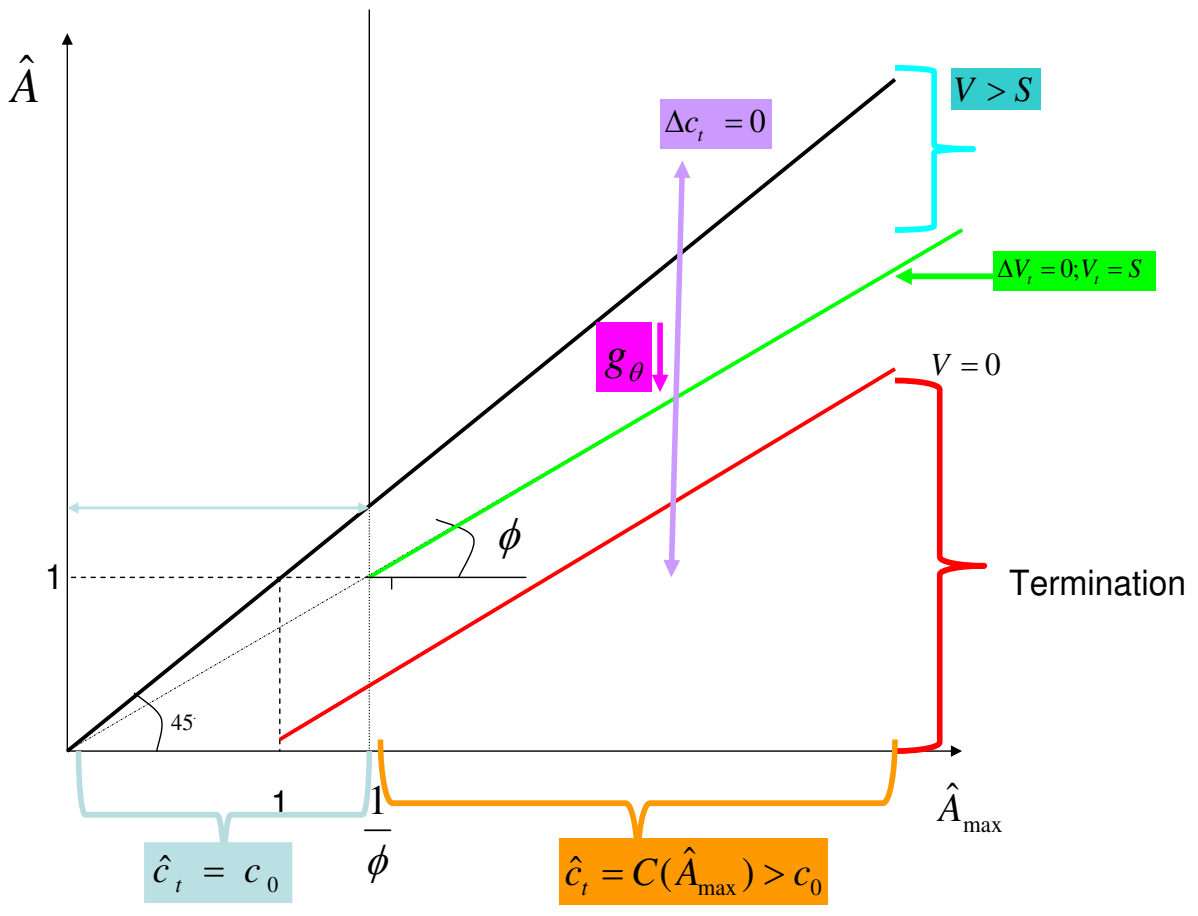




\section{Figure 2: Optimal Compensation Contract}

The left panel plots the current productivity $A_{t}$ (y-axis) against the running maximum $A_{\max , t}$ (x-axis). The right panel figure plots the evolution of the optimal current consumption of the manager $\widetilde{c}$ (dashed line) alongside the evolution of the establishment's organizational capital $\widehat{A}$ (full line). The latter is a measure of size and productivity of the establishment. The two time-series are produced by simulating model for 300 periods (horizontal axis) under the benchmark calibration described below $(\phi=.5)$, except that the time discount rates of owners and managers are held equal: $\rho_{o}=\rho_{m}$.
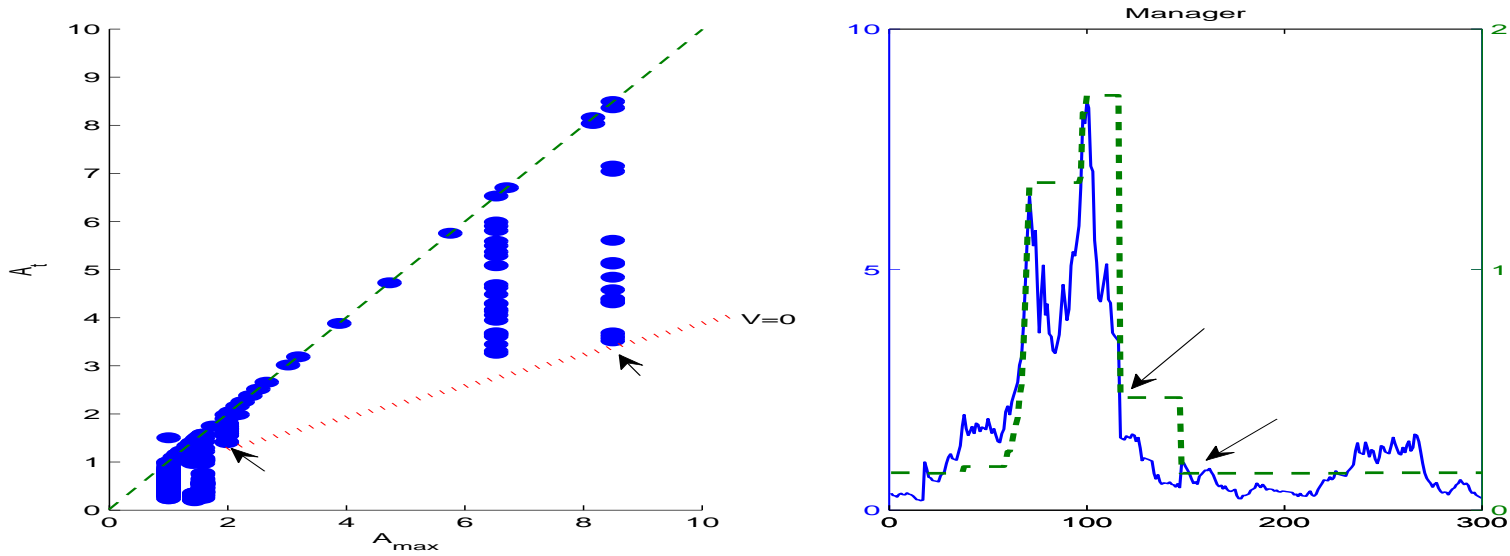

Figure 3: Payouts to Manager and Owner

The left panel plots the evolution of the optimal current consumption of the manager $\widetilde{c}$ (dashed line, measured against the right axis) alongside the evolution of the establishment's organizational capital $\widehat{A}$ (full line, measured against the left axis). The right panel plots the payouts to the owner $\widetilde{\pi}$. The two time-series are produced by simulating the model for 300 periods (horizontal axis) under the benchmark calibration described below, except that the time discount rates of owners and managers are held equal: $\rho_{o}=\rho_{m}$.
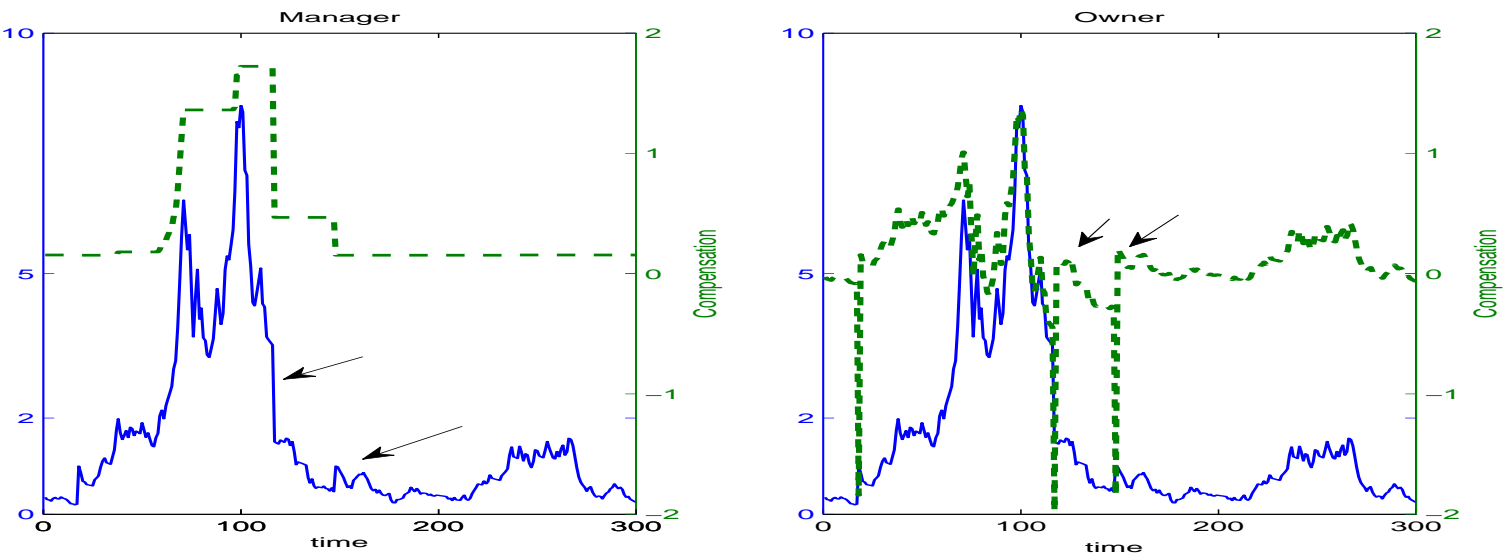
Figure 4: Payouts to Manager and Owner: Discount Rate Wedge

The left panel plots the evolution of the optimal current consumption of the manager $\widetilde{c}$ (dashed line, measured against the right axis) alongside the evolution of the establishment's organizational capital $\log \widehat{A}$ (full line, measured against the left axis). The right panel plots the payouts to the owner $\widetilde{\pi}$. The two time-series are produced by simulating the model for 300 periods (horizontal axis) under the benchmark calibration described below, except that the time discount rates of owners and managers are held equal: $\rho_{o}<\rho_{m}$.
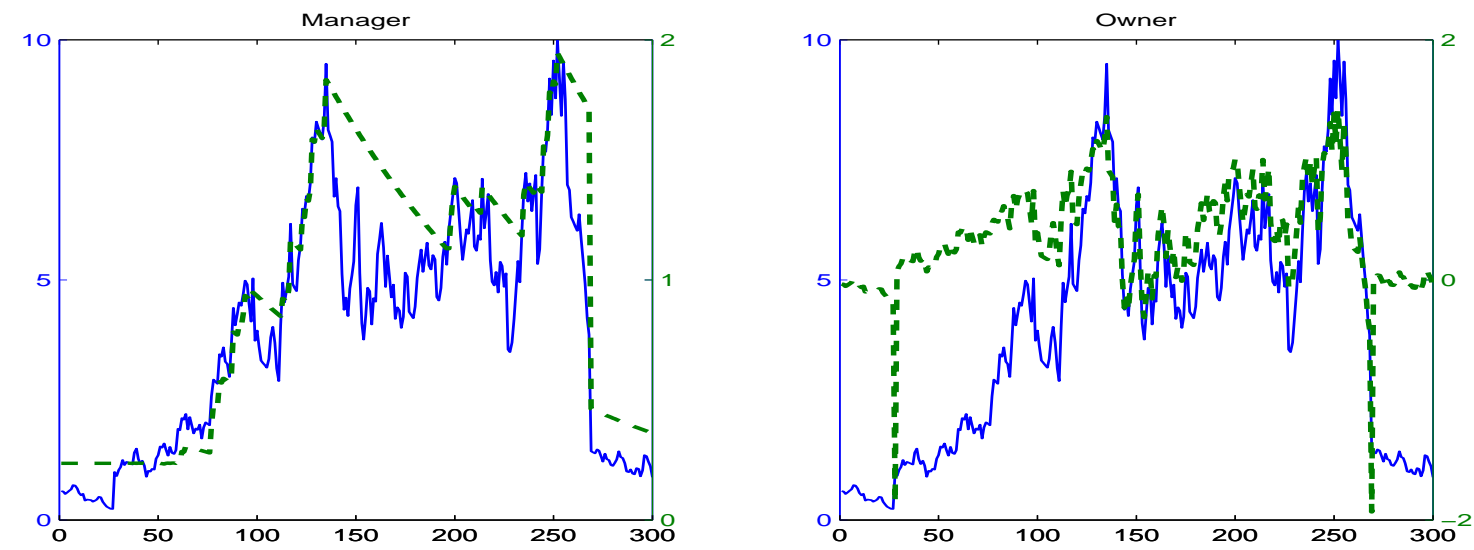

Figure 5: Excess Reallocation Rate

The blue bars show the excess reallocation rate for the manufacturing sector, constructed by Faberman (2006). The excess job reallocation rate is a direct measure of the cross-sectional dispersion of establishment growth rates. It is defined as the sum of the job creation rate plus the job destruction rate less the net employment growth rate. The Faberman data are extended to 2007.III using BLS data. The red bars show the excess reallocation rate for the private sector (BLS).

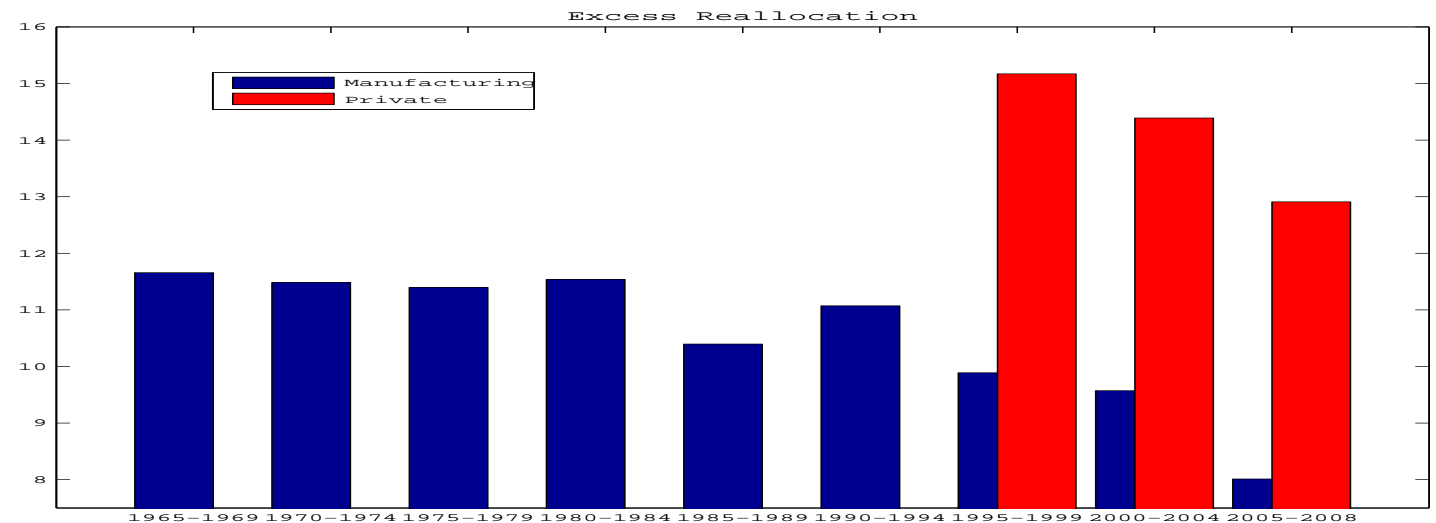




\section{Figure 6: From Low-Powered to High-Powered Incentives}

Plot of log compensation against log size of establishment. The left panel shows the initial steady-state growth path (high vintage-specific growth). The right panel shows the new steady-state growth path (high general productivity growth). The data are generated from the model under its benchmark calibration.
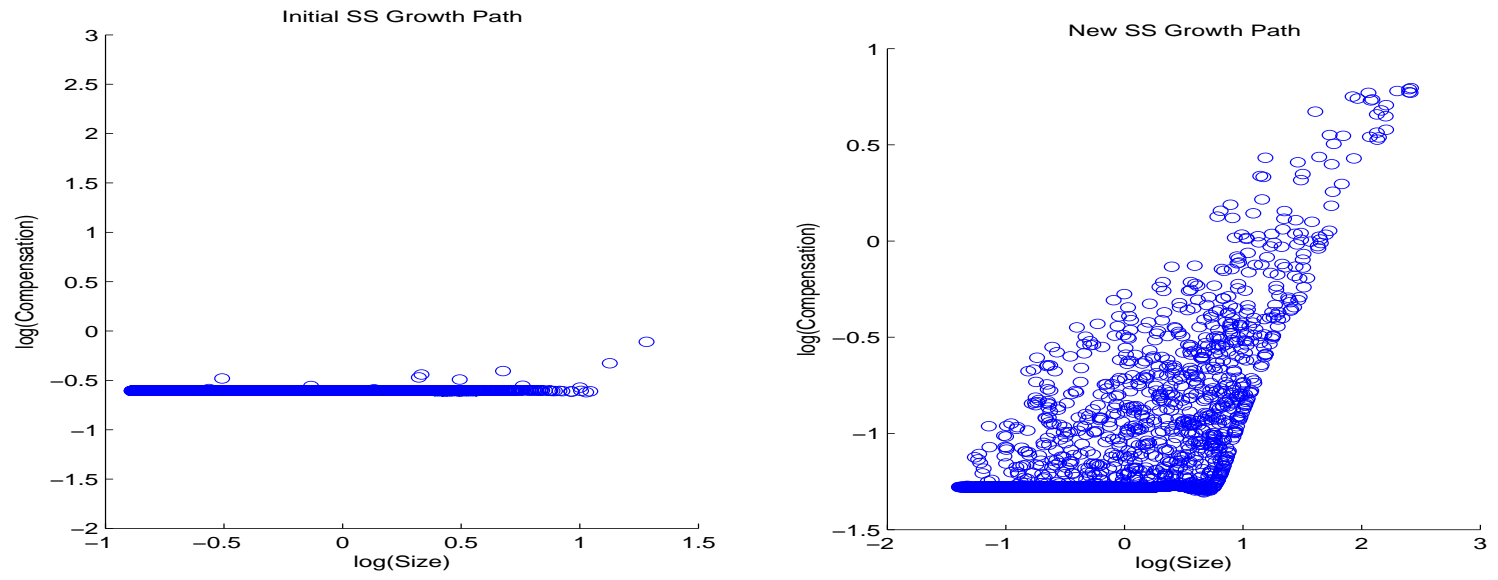

Figure 7: Compensation and Size Distribution on the New Steady State Growth Path

Histogram of log compensation and log size of establishments. The data are generated by simulating the model's new steady-state growth path(high general productivity growth) under its benchmark calibration.
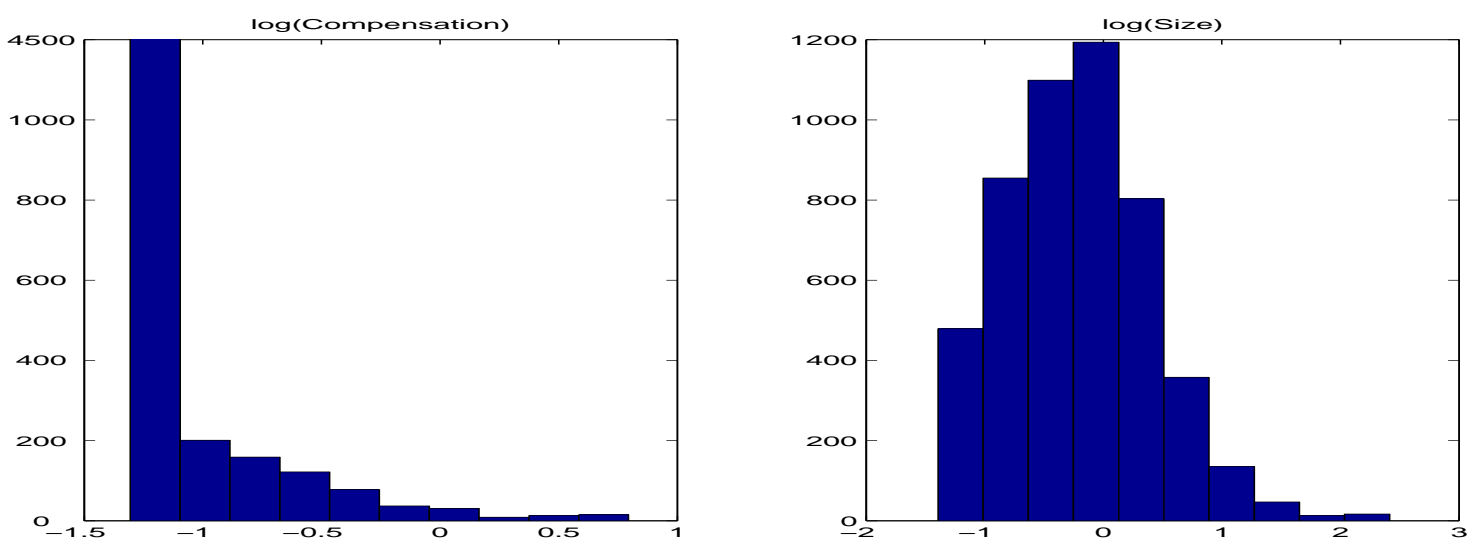
Figure 8: Size Distribution in the New Steady State

The figure plots the relationship between the log size of establishments on the horizontal axis and the rank in the distribution $\log (\operatorname{Rank}-.5)$ on the vertical axis. The figure is for the new steady state growth path under our benchmark calibration.

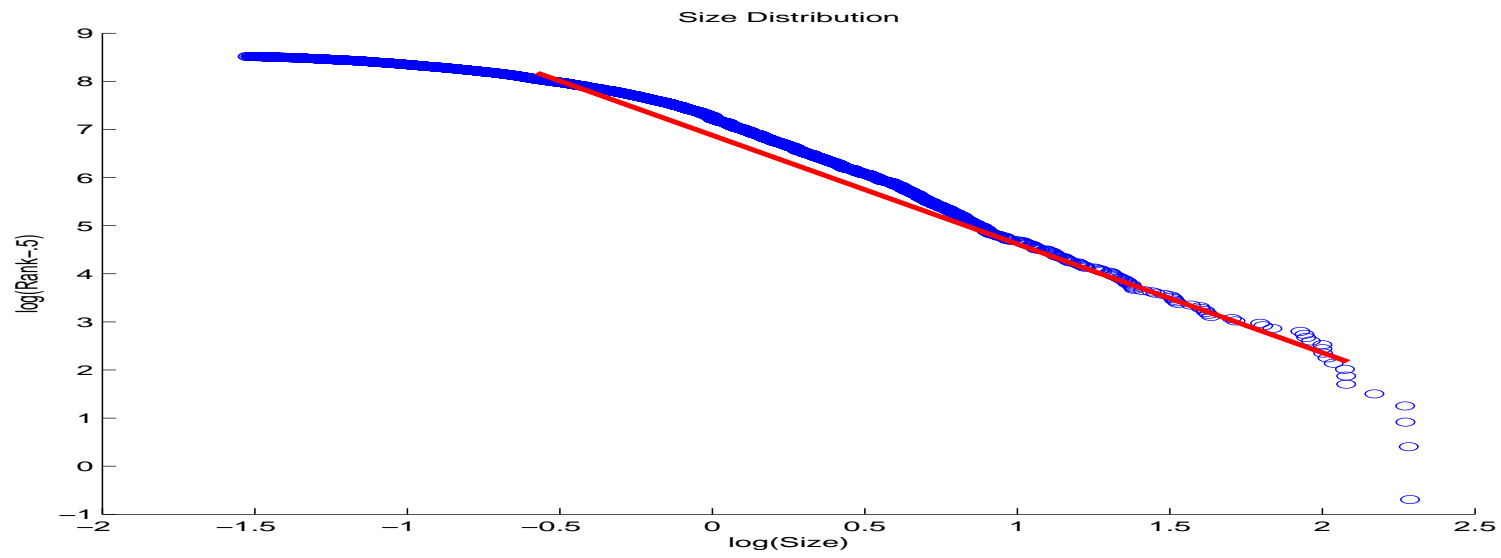

Figure 9: Cross-section

Scatter plot of steady-state growth path Tobin's q against the standard deviation of log compensation for 13 industries with $g_{\theta}$ varying from low $(.00 \%)$ on the right side to high $(6.82 \%)$ on the left side. The results are for the benchmark parameters.

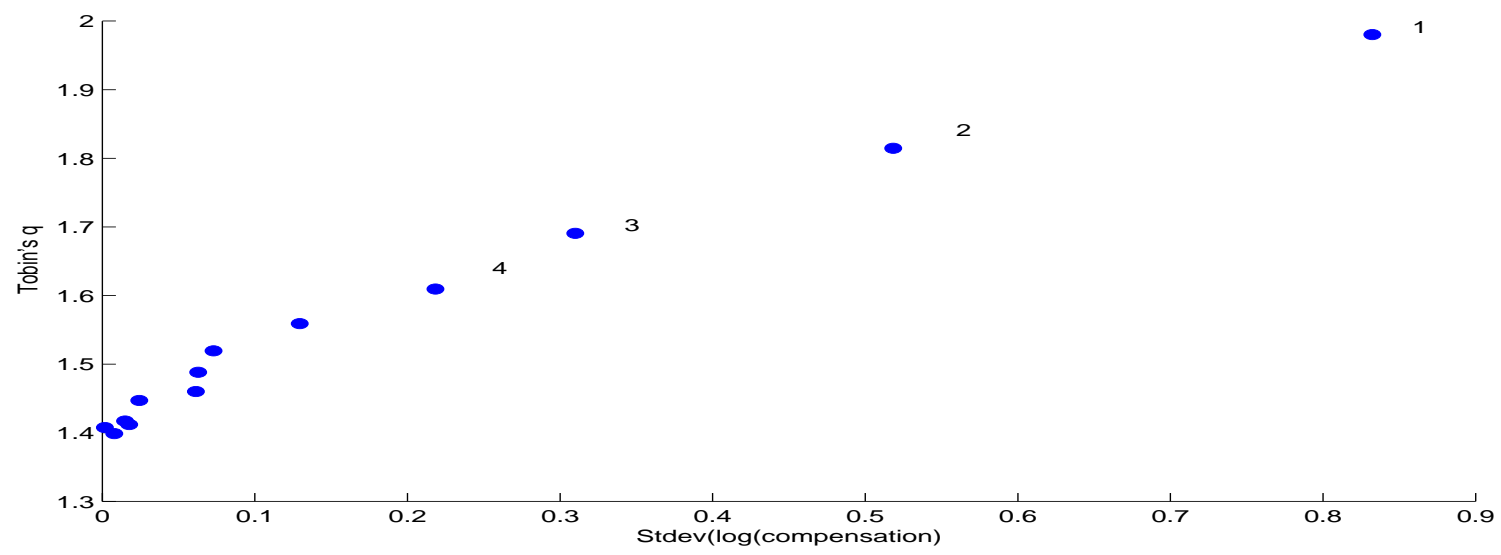

